\title{
Surface-Altered Zeolites as Permeable Barriers for In Situ Treatment of Contaminated Groundwater
}

\author{
Phase IIB Topical Report
}

For Period May 2000-March 2002

\author{
By \\ Robert S. Bowman \\ Pengfei Zhang \\ Xian Tao
}

Issued on: March 2002

DOE Award: DE-AR21-95MC32108

\begin{abstract}
Submitted by
New Mexico Institute of Mining and Technology

801 Leroy Place; Socorro, New Mexico 87801
\end{abstract}

Subcontractors

Richard L. Johnson

Oregon Science and Health University; Beaverton, Oregon

Douglas Wolf

University of Dayton Research Institute; Dayton, Ohio 


\section{Disclaimer}

This report was prepared as an account of work sponsored by an agency of the United States Government. Neither the United States Government nor any agency thereof, nor any of their employees, makes any warranty, express or implied, or assumes any legal liability or responsibility for the accuracy, completeness, or usefulness of any information, apparatus, product, or process disclosed, or represents that its use would not infringe privately owned rights. Reference herein to any specific commercial product, process, or service by trade name, trademark, manufacturer, or otherwise does not necessarily constitute or imply its endorsement, recommendation, or favoring by the United States Government or any agency thereof. The views and opinions of authors expressed herein do not necessarily state or reflect those of the United States Government or any agency thereof. 


\section{Abstract}

This report summarizes experiments to develop and test surfactant-modified zeolite/zerovalent iron (SMZ/ZVI) pellets for permeable reactive barriers to treat groundwater contamination. Coating a glass foam core with a mixture of hexadecyltrimethylammonium surfactant, zeolite, and ZVI produced a high hydraulic conductivity, mechanically stable pellet. Laboratory experiments showed that the pellets completely removed soluble chromate from aqueous solution, and reduced perchloroethylene (PCE) concentrations more than pellets that lacked surfactant. Based upon the laboratory results, we predicted a 1-m-wide SMZ/ZVI barrier would reduce PCE concentrations by four orders of magnitude.

Thirteen cubic meters (470 cubic feet) of SMZ/ZVI pellets were manufactured and emplaced in a permeable barrier test facility. A controlled plume of chromate and PCE was allowed to contact the barrier for four weeks. The entire plume was captured by the barrier. No chromate was detected downgradient of the barrier. The PCE broke through the barrier after four weeks, and downgradient concentrations ultimately exceeded $10 \%$ of the influent PCE. The less-than-expected PCE reduction was attributed to insufficient surfactant content, the large size, and $\mathrm{pH}$-altering characteristics of the bulk-produced pellets. The pellets developed here can be improved to yield a performance- and cost-competitive permeable barrier material. 


\section{Table of Contents}

Page

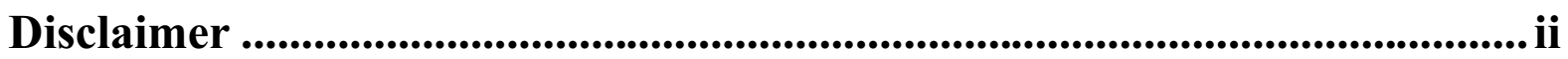

Abstract ............................................................................................................................ iii

Table of Contents ........................................................................................................ iv

List of Figures ........................................................................................................... vi

List of Tables ................................................................................................... vii

Executive Summary ............................................................................................................ 1

Experimental ............................................................................................................ 3

Development of Prototype SMZ/ZVI Pellet Formulations............................................3

Process Development ......................................................................................... 3

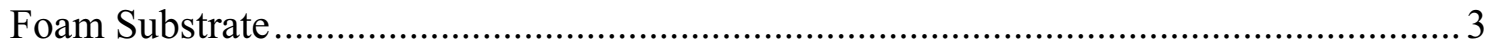

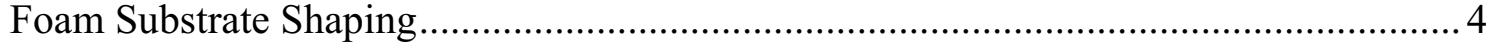

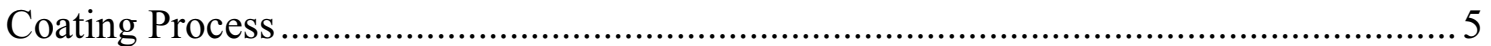

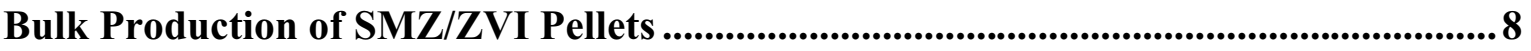

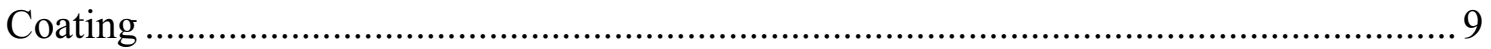

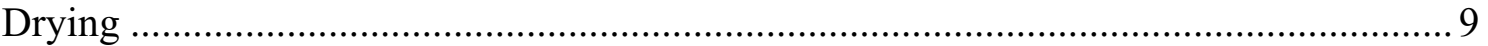

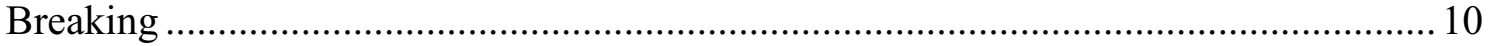

Laboratory Testing of Bulk-Produced SMZ/ZVI Pellets ............................................ 10

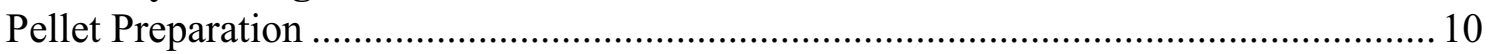

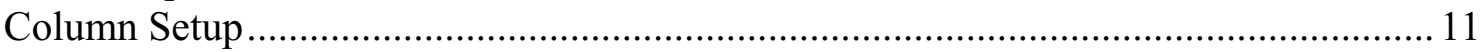

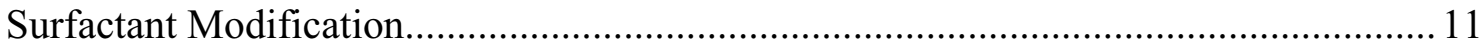

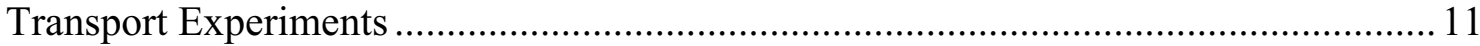

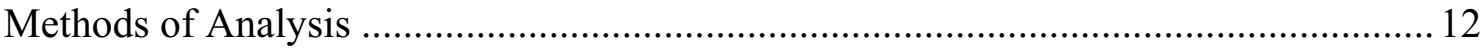

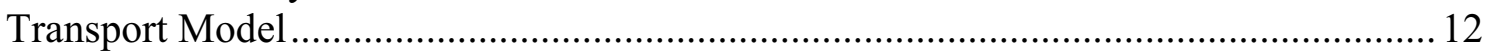

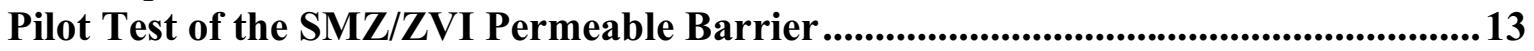

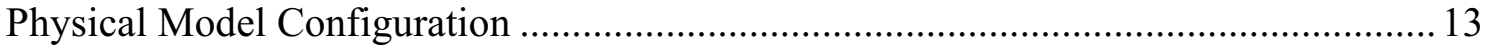

Flow Control System and Sampling Array ................................................................ 14

Preparation for Contaminant Injection and Sampling ........................................... 15

Contaminant Injection, Sampling, and Analyses .............................................. 16

Results and Discussion ........................................................................................ 19

Laboratory Testing of Bulk-Produced SMZ/ZVI Pellets ............................................. 19

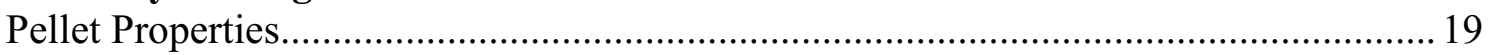

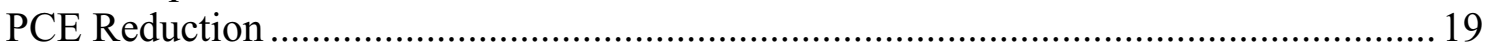

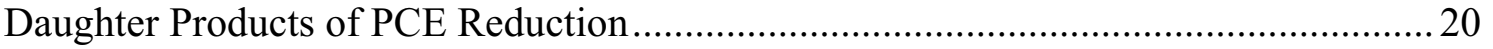

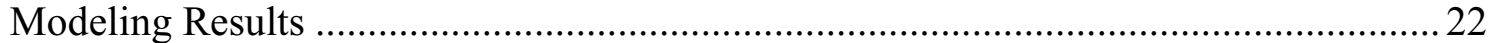

Pilot Test of the SMZ/ZVI Permeable Barrier ............................................................25

Conclusions ............................................................................................................. 29

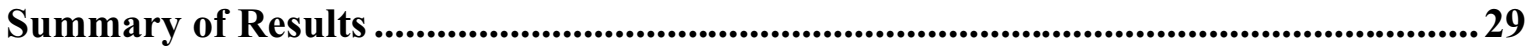


Recommendations for Future Work ................................................................................2 29

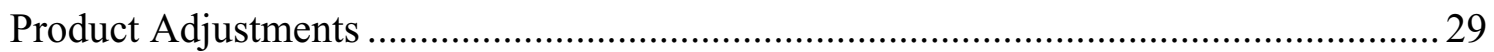

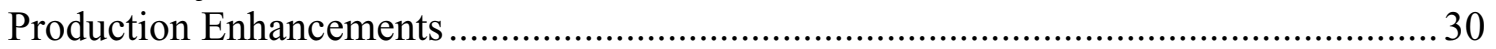

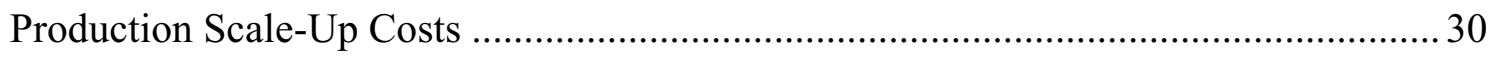

References .................................................................................................... 31

Acronyms and Abbreviations .................................................................. 33 


\section{List of Figures}

Figure 1. Schematic diagrams of small and large mixing baths for zeolite/iron/surfactant coating

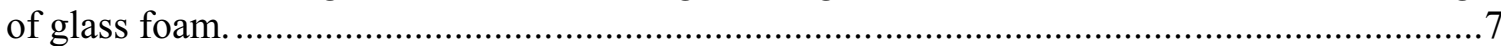

Figure 2. Photograph of the propeller used in the small and large mixing baths.......................... 8

Figure 3. Schematic diagram of the bulk production process for SMZ/ZVI pellets. ....................9

Figure 4. Plan and cross-section views of the PRB pilot-test facility. Brown circles are sampling locations, purple circles are injection and extraction well locations, and red circles are contaminant injection locations. Groundwater flow is from left to right.

Figure 5. Schematic drawing of the injection control system showing both the groundwater flow

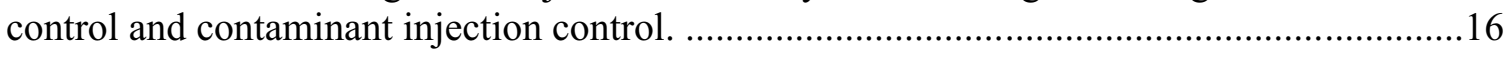

Figure 6. Photograph of the groundwater injection control system. .........................................17

Figure 7. Photograph of the contaminant injection system. ...................................................... 17

Figure 8. Photograph of the groundwater extraction pumps. ................................................17

Figure 9. Effluent PCE concentrations during PCE reduction at various flow rates: (a) $0.5 \mathrm{~m} \mathrm{~d}^{-1}$, (b) $1.0 \mathrm{~m} \mathrm{~d}^{-1}$, and (c) $1.9 \mathrm{~m} \mathrm{~d}^{-1}$. The smooth curves are the best-fit simulations using HYDRUS 1-D. Effluent PCE concentrations were significantly lower in the surfactantmodified (SM) columns than in the unmodified (UM) columns

Figure 10. Effluent TCE concentrations during PCE reduction at various flow rates: (a) $0.5 \mathrm{~m} \mathrm{~d}^{-1}$, (b) $1.0 \mathrm{~m} \mathrm{~d}^{-1}$, and (c) $1.9 \mathrm{~m} \mathrm{~d}^{-1}$. TCE production due to PCE reduction was significantly higher in the surfactant-modified (SM) columns than in the unmodified (UM) columns.......21

Figure 11. Effluent cis-DCE concentrations during PCE reduction at various flow rates: (a) $0.5 \mathrm{~m}$ $\mathrm{d}^{-1}$, (b) $1.0 \mathrm{~m} \mathrm{~d}^{-1}$, and (c) $1.9 \mathrm{~m} \mathrm{~d}^{-1}$. Cis-DCE generation during PCE reduction was significantly higher in the surfactant-modified (SM) columns than in the unmodified (UM) columns.

Figure 12. Relationship between PCE reduction rate constant $\mu_{T}$ and pore water velocity. Solid lines represent best linear fits. The $95 \%$ confidence limits for $\mu_{T}$ fall inside the symbols. .....23

Figure 13. Simulated breakthrough curves for a hypothetical reactive solute using Eq. (3) with different dispersivity $\left(\alpha_{L}\right)$ values. Other transport parameter values $\left(L=0.3 \mathrm{~m}, v=0.5 \mathrm{~m} \mathrm{~d}^{-1}\right.$, $\theta=0.81, \rho_{b}=0.67 \mathrm{~g} \mathrm{~cm}^{-3}, \mu_{T}=0.4 \mathrm{hr}^{-1}$, and $K_{d}=1.0 \mathrm{~L} \mathrm{~kg}^{-1}$ ) were identical. Steady-state break-through concentration increases with increasing dispersivity.

Figure 14. Simulated concentration of PCE downgradient of a 1 -m-thick SMZ/ZVI barrier intercepting a $500 \mu \mathrm{g} \mathrm{L}^{-1}$ PCE plume, using Eq. (3). Transport parameters $v=0.5 \mathrm{~m} \mathrm{~d}^{-1}, \theta=$ $0.81, \rho_{b}=0.67 \mathrm{~g} \mathrm{~cm}^{-3}, \mu_{T}=0.4 \mathrm{hr}^{-1}$, and $\left.K_{d}=1.8 \mathrm{~L} \mathrm{~kg}^{-1}\right)$.

Figure 15. Chromate and PCE distributions following 3-6 days of contaminant injection...........26

Figure 16. Chromate and PCE distributions following 12-15 days of contaminant injection.......26

Figure 17. Chromate and PCE distributions following 19-22 days of contaminant injection.......27

Figure 18. Chromate and PCE distributions following 26-29 days of contaminant injection.......27

Figure 19. Chromate and PCE distributions following 33-36 days of contaminant injection.......28 


\section{List of Tables}

Table 1. Particle size distribution of Peerless iron powder used to manufacture SMZ/ZVI pellets.

Page

Table 2. Batch formulation of ingredients used in mixing baths for glass foam coating. ...............8

Table 3. Composition of SMZ/ZVI pellets bulk-produced at UDRI. .........................................10

Table 4. Locations of multi-level samplers in the pilot-test tank. Distances measured from origin at bottom SW corner of tank. Barrier extends from $(3.47,2.26,1.00)$ to $(4.47,8.26,3.00)$...15

Table 5. Transport parameter values determined by inverse modeling of the experimental breakthrough data. The number following the \pm sign represents the $95 \%$ confidence limit. ..22 


\section{Executive Summary}

The purpose of this research was to develop and test a combined surfactant-modified zeolite/zero-valent iron (SMZ/ZVI) pellet for groundwater contaminant destruction in subsurface permeable reactive barriers (PRBs). The investigation consisted of laboratory tests followed by a pilot-scale test of an SMZ/ZVI barrier. The research was motivated by prior laboratory results indicating that enhanced contaminant removal was achieved by combining SMZ and ZVI, compared to using either of these materials alone. In addition, production of a SMZ/ZVI pellet offered opportunities to produce a permeable barrier material with superior hydraulic and mechanical properties.

Prototype SMZ/ZVI formulations were prepared and tested by the New Mexico Institute of Mining and Technology (NMT) in collaboration with the University of Dayton Research Institute (UDRI). Based on these preliminary studies, a pellet formulation based on a high porosity, high permeability glass foam core was chosen for large-scale production and testing. Cercona of America, of Dayton, OH, produced the glass-foam material. Glass-foam slabs were coated by UDRI with a slurry of zeolite, zero-valent iron, and the surfactant hexadecyltrimethylammonium chloride (HDTMA-Cl), and broken into 25-mm (1-in) cubes. The final pellet composition by weight was $16 \%$ zeolite, $49 \%$ ZVI, $0.7 \%$ HDTMA-Cl, and $34 \%$ glass foam. Ultimately, about 13 cubic meters ( 470 cubic feet) of SMZ/ZVI pellets were produced by UDRI.

The hydraulic and contaminant-removal properties of the SMZ/ZVI pellets were characterized in a series of laboratory column experiments. The hydraulic conductivity of the pellets was greater than $0.01 \mathrm{~m} \mathrm{~s}^{-1}$, and they showed excellent mechanical strength. The pellets reduced aqueous chromate concentrations to nondetectable levels. In a series of experiments at different flow rates, the SMZ/ZVI pellets showed a three-fold increase in perchloroethylene (PCE) reduction rates compared to pellets that did not contain surfactant. Daughter products of PCE reduction accumulated more rapidly in the presence of surfactanttreated pellets, indicating that the surfactant/ZVI combination caused a change in the PCE dechlorination pathway. Based on the laboratory column results, we predicted that a $1-\mathrm{m}$ wide SMZ/ZVI pellet barrier would reduce influent PCE concentrations by four orders of magnitude, from $500 \mu \mathrm{g} \mathrm{L}^{-1}$ to less than $0.03 \mu \mathrm{g} \mathrm{L}^{-1}$.

A pilot-scale test was conducted in the Oregon Graduate Institute (OGI) Large Experimental Aquifer Program PRB pilot-scale testing facility. The overall dimensions of the pilot-test tank were $8.5-\mathrm{m}$ wide by $8.5-\mathrm{m}$ long by $3-\mathrm{m}$ deep. The sand-filled tank was heavily instrumented for water flow control and three-dimensional chemical sampling. A SMZ/ZVI permeable barrier 2-m deep by 1-m thick by 4-m long was emplaced in the center of the tank transverse to water flow. A controlled groundwater flow velocity of $0.5 \mathrm{~m} \mathrm{~d}^{-1}$ was provided by injection and withdrawal wells at opposite ends of the tank.

A mixed plume of chromate $\left(6 \mathrm{mg} \mathrm{L}^{-1}\right)$ and PCE $\left(500 \mu \mathrm{g} \mathrm{L}^{-1}\right)$ was injected into the tank for a period of five weeks. The development of the plume and its capture by the barrier was tracked by weekly sampling along several transects. At the end of the five-week test period, no chromate had penetrated the SMZ/ZVI barrier. In contrast, PCE broke through the barrier within four weeks, and downgradient concentrations in some cases were greater than 
$50 \mu \mathrm{g} \mathrm{L}^{-1}$. The barrier behaved well from a hydraulic standpoint, fully capturing the contaminant plume.

The unexpected rapid breakthrough of PCE in the pilot test is attributed to three factors. First, the bulk-produced pellets did not contain the optimum amount of HDTMA-Cl, allowing faster migration of PCE through the barrier and lower PCE reduction rate constants. Second, the relatively large size of the SMZ/ZVI cubes $(25 \mathrm{~mm}$ on each side) resulted in unfavorable mass transfer kinetics between water flowing through the barrier and the reactive pellet interiors. Third, the glass foam core released significant amounts of base, raising the $\mathrm{pH}$ within the barrier and further lowering the dechlorination rate for PCE.

The results indicate that SMZ/ZVI pellets show considerable promise for permeable barrier applications, but that additional development work, particularly on large-scale production, is required. Preliminary estimates indicate that SMZ/ZVI pellets could be manufactured in large quantities for a cost of about $\$ 10$ per cubic foot or $\$ 350$ per cubic meter, making them competitive for permeable barrier applications. 


\section{Experimental}

\section{Development of Prototype SMZ/ZVI Pellet Formulations Process Development}

The initial task of this effort was the formulation of a SMZ/ZVI pellet that would produce a permeable barrier with the appropriate reactivity, hydraulic conductivity, and mechanical stability. The search for a suitable material began with the examination of SMZ/ZVI pellets produced by Cercona of America, Inc. (Dayton, OH). These pellets had shown success in laboratory batch experiments ( $\mathrm{Li}$ et al. 1999), but were less successful in a small-scale permeable barrier pilot test (Bowman et al. 1999). The major deficiency of the Cercona pellets was in the area of mechanical strength. The Cercona pellets showed a tendency to crumble easily when handled roughly and with prolonged contact with aqueous solutions. Some containers of pellets arrived at their destination as a coarse powder rather than an intact pellet.

In an effort to improve the mechanical stability of the SMZ/ZVI pellets, a new material being produced by Cercona was examined for feasibility. This material, a glass foam structure marketed under the name Cell-Pore ${ }^{\mathrm{TM}}$, has a high hydraulic conductivity and high mechanical strength. Initial experiments with this material showed that as water flowed through the open glass foam structure, it was able to make contact with a much larger surface area than in the earlier SMZ/ZVI pellets. We therefore directed our efforts toward developing a method to coat the glass foam with an iron/zeolite/surfactant material.

We tested coating glass foam pieces directly with a zeolite/iron/surfactant slurry without added binder. The drying of the coated foam pieces allowed some of the iron to oxidize, bonding the iron and zeolite to the glass foam. It was also observed that not only had the slurry actually flowed into the foam pieces rather than simply coating them, but it had also done so without significantly clogging the pore structure. When immersed in water, the foam pieces remained intact.

The experiments with the coated glass foam produced pieces that met the criteria for hydraulic conductivity and mechanical strength. An additional advantage of using the glass foam was that this product was already being regularly produced by Cercona and required no extensive redevelopment. Because their production process generated a significant amount of scrap material, Cercona was willing to provide large quantities of the glass foam to the project at no charge. This proved to be very important in the initial stages of process and procedure development. Upon reaching the production stage of the project, UDRI was able to purchase large quantities of the glass foam material from Cercona at sufficient intervals to sustain UDRI production of coated pieces while not disrupting Cercona's production of the glass foam.

\section{Foam Substrate}

The Cell-Pore ${ }^{\mathrm{TM}}$ technology is a patented process (Helferich 1987) based on the gelation of soluble silicates with soluble aluminates. The combination of these two aqueous solutions gels in a reproducible and controllable manner depending on the specific concentration, temperature, and ratio of each material. The ceramic glass foam is made by first preparing two separate slurries, one based on silicate and the other based on aluminate. The slurries are 
prepared by combining sodium silicate and sodium aluminate separately with recycled glass powders, calcium compounds, additional silicate materials, special surfactants, and a gassing agent. Once prepared, the two slurries are stored at $12^{\circ} \mathrm{C}$ until they are ready to be combined. When combined, a room-temperature reaction takes place in which a gas is produced causing the combined slurries to expand to four times their original volume. The reaction ultimately produces a porous sodium aluminosilicate gel. After approximately $15 \mathrm{~min}$ at room temperature, the gelled mass gains sufficient strength to be removed from a mold, dried, and eventually fired.

The drying process takes place over a 48-h period in a temperature and humidity controlled drying oven. Over the 48 -h drying period, the temperature is varied from $110^{\circ} \mathrm{C}$ to $130^{\circ} \mathrm{C}$. The humidity level starts at $55 \%$ and is reduced to $10 \%$ by the end of the drying cycle.

The sodium aluminosilicate material is then fired at $850^{\circ} \mathrm{C}$ for 24 hours. The $850^{\circ} \mathrm{C}$ temperature is sufficient to sinter the foamed shape. This temperature was also selected because it gives the most surface area with the minimum amount of sodium leachability.

After firing, the resulting material's final composition is a high-alumina soda-lime glass with an approximate composition of $15 \% \mathrm{Na}_{2} \mathrm{O}, 10 \% \mathrm{CaO}, 5-8 \% \mathrm{Al}_{2} \mathrm{O}_{3}, 65+\% \mathrm{SiO}_{2}$, plus small amounts of $\mathrm{MgO}, \mathrm{TiO}_{2}, \mathrm{Fe}_{2} \mathrm{O}_{3}$, and $\mathrm{MnO}_{2}$.

\section{Foam Substrate Shaping}

Size and shape of the glass foam structures were seen as important issues from the outset of the production effort. The first goal was to establish what size and shape would be most effective in the permeable barrier pilot test. Several ideas were considered. A granular material with a diameter on the order of 3-6 mm (1/4-1/8 in) was considered optimal for providing high hydraulic conductivity along with contaminant access to the reactive internal pellet surfaces. Due to difficulties in economically and consistently breaking larger foam slabs into these small particles, a 25-mm (1-in) cube was selected for large-scale production.

Once the cube shape was chosen, the next issue to consider was the optimum glass foam shape for Cercona to produce. Experiments showed that the most effective means of coating the substrate was to place it into a bath of zeolite/iron/surfactant slurry and allow the slurry to soak into the glass foam. The raw material configuration had to be conducive to the dipping process and also allow easy conversion to the $25-\mathrm{mm}$-cube pieces. Initially, small cubes were used to make prototype pieces for laboratory experiments. The small sized pieces proved to be cumbersome to work with in the dipping process. The major difficulty was in handling the small pieces in the slurry bath. New design ideas had to be considered since the scale-up plans called for a much larger bath to be used in the production mode.

Cercona was able to supply several scrap pieces for shape experimentation. The pieces were irregularly shaped and of various sizes, but most of the pieces were $25-\mathrm{mm}$ thick. Experiments were conducted with whole pieces with the assumption that the large pieces could be broken or cut into shapes similar to the $25-\mathrm{mm}$ cubes after coating. It was quickly learned that the coating added significant strength to the material, which made it extremely difficult to break the large pieces into smaller pieces by hand. Cutting the coated pieces by hand was also difficult. Pieces could be broken relatively easily when first removed from the bath, but this method reduced the efficiency of the process because each piece had to be 
broken immediately after dipping. It was decided that this procedure could not be used when the process moved to actual production due to time considerations.

The next experiment involved cutting slots into the scrap pieces before dipping them into the slurry bath. The slots were cut into the substrate pieces using a hacksaw. Several experiments were performed to determine the optimum depth for the slots to be cut. Shallow cuts into the material showed the same difficulties in breaking off smaller pieces as the unslotted material. Pieces with slots that were too deep were very fragile and often broke when dipped into the bath. The optimum cut depth was eventually determined to be about half way through the slab. This cut depth provided enough strength for the material to survive the dipping process intact and also allowed for the dried materials to be broken with significantly less effort. It was further determined that when these slots were cut into one side, the breaking process could be enhanced by cutting another series of half inch slots on the opposite side of the substrate at a $90^{\circ}$ angle to the slots on the first side.

This procedure continued through the experimental stages and into the beginning of the production stage. Slots were cut by hand into both sides of every piece for the first several weeks of production. Once all other factors in the production scale-up were in place, the purchase of glass foam slabs from Cercona began. It was determined that pieces $230-\mathrm{mm}$ (9-in) square by 25 -mm thick would be advantageous for use in the dipping operation. Cercona could also easily produce this configuration on a large scale without altering production of their other products. As Cercona's production of the 230-mm-square slabs began, the possibility of pre-slotting the slabs was investigated. While Cercona explored ways to produce the slotted slabs, the process of cutting grooves into the slabs by hand continued. Eventually, Cercona came up with a gang saw configuration that could easily cut the slots into the material prior to shipping. This substrate design, 230-mm square and 25-mm thick with the "grid" pattern of slots, was chosen as the optimum shape and size for the full-scale production process. These slabs easily fit into the selected slurry bath chamber for dipping and could easily be broken into $25-\mathrm{mm}$ cubes when dried.

\section{Coating Process}

\section{Raw Materials}

When the decision to use the glass foam substrate as the core for the reactive medium was made, work began on developing a process for coating the glass foam substrates. The first task to be completed was the selection of the proper zeolite/iron/surfactant formulation.

One-hundred-twenty 50-lb bags of -40 mesh $(<0.4-\mathrm{mm})$ zeolite (Lot Number 00-5004) were obtained from the St. Cloud Mining Company, Truth or Consequences, NM. The zeolite consisted of roughly $74 \%$ clinoptilolite, $10 \%$ feldspar, $10 \%$ quartz and cristobalite, $5 \%$ smectite, and 1\% illite (Sullivan et al. 1997). The zeolite had a BET surface area of $15.1 \mathrm{~m}^{2} \mathrm{~g}^{-1}$ (determined using a Flowsorb 2300 BET surface area analyzer, Micromeritics, Norcross, GA). ZVI was obtained from Peerless Metal Powders and Abrasive (Detroit, MI). The surfactant was Carsoquat CT-429 (29-30\% hexadecyltrimethylammonium chloride (HDTMA-Cl) by weight in water), Lot Number F9225278, manufactured by Lonza, Inc. of Fair Lawn, NJ. The surfactant was shipped to UDRI from NMT in two 55-gallon drums.

Peerless Metal Powders and Abrasive provided several samples of iron powders for the initial experiments. This company expressed a genuine interest in assisting UDRI with this project. Several other metal companies were contacted, but either did not have a suitable 
product for this application or were not interested in providing materials for this project. Sample materials from Peerless ranged from a very coarse iron aggregate to a fine iron powder.

It was originally believed that the coarser material would allow for greater iron mass and might ultimately provide greater reactivity, so the initial focus was placed on making a slurry using the coarse iron. An early problem with the coarse iron was that it showed a tendency to settle in the bottom of the slurry bath. Some changes were made in the mixing process to attempt to create a vortex that would keep the coarse particles in suspension, but the settling effect could never be completely eliminated.

The finer powders produced a more homogenous slurry when mixed with the zeolite, surfactant, and water. As a compromise, Peerless provided a sample containing both coarse and fine particles, but the settling issue still could not be resolved. One of the Peerless iron powders, identified as Cast Iron Aggregate Size -70 P1, was eventually determined to be the best iron powder to use in this application. The particle size of the iron is shown in Table 1. The BET surface area of this iron was determined to be $1.76 \mathrm{~m}^{2} \mathrm{~g}^{-1}$.

Table 1. Particle size distribution of Peerless iron powder used to manufacture SMZ/ZVI pellets.

\begin{tabular}{cc}
\hline Sieve Size & \% Particle Size \\
\hline 60 & 0 \\
70 & 0 \\
80 & 7 \\
100 & 14 \\
120 & 20 \\
200 & 37 \\
$<200$ & 22 \\
\hline
\end{tabular}

Peerless had also been working on a process to reduce the amount of oxide on the surface of the iron particles and later sent a sample of the material for evaluation. This material had the appearance of shiny metal shavings as opposed to black flakes. The oxide and carbon levels were significantly lower than had been observed in previous Peerless samples. This material was available only as the coarse product, but even if it had been available in the fine size, it would not have been practical to change materials at this point in the process.

\section{Mixing}

Upon completion of the substrate and formulation selections, the first major issue to be addressed was the mixing of raw materials to form the proper slurry. Special attention needed to be paid to obtaining the proper vortex in the slurry bath to hold all materials in suspension and maintain a homogenous slurry.

A standard laboratory stirrer, Arrow Engineering (Hillside, NJ) Model 850 was used in the initial flow design experiments. The original bath chamber was a 300-mm (12-in)-long piece of 150-mm (6-in)-diameter acrylic tubing attached to an acrylic base. Experiments were conducted using glass beads in water. The glass beads simulated the dry ingredients. Observations were made as to how the beads moved in the water under different mixing 
conditions. Variables involved were mixer speed, paddle position, propeller angle, and water level. After consulting with faculty of the Department of Chemical Engineering at the University of Dayton, it was determined that the addition of baffle plates to the inside of the chamber would assist in redirecting the flow to the center, thus producing a more optimal agitation pattern. Several test slurries were produced under varying mixing conditions. Experiments continued until the proper mixer position and paddle configuration were selected that produced a slurry with optimum properties. A larger mixing bath, $300-\mathrm{mm}$ (12-in) diameter, was also constructed. Schematic diagrams of the small and large mixing baths are shown in Figure 1.
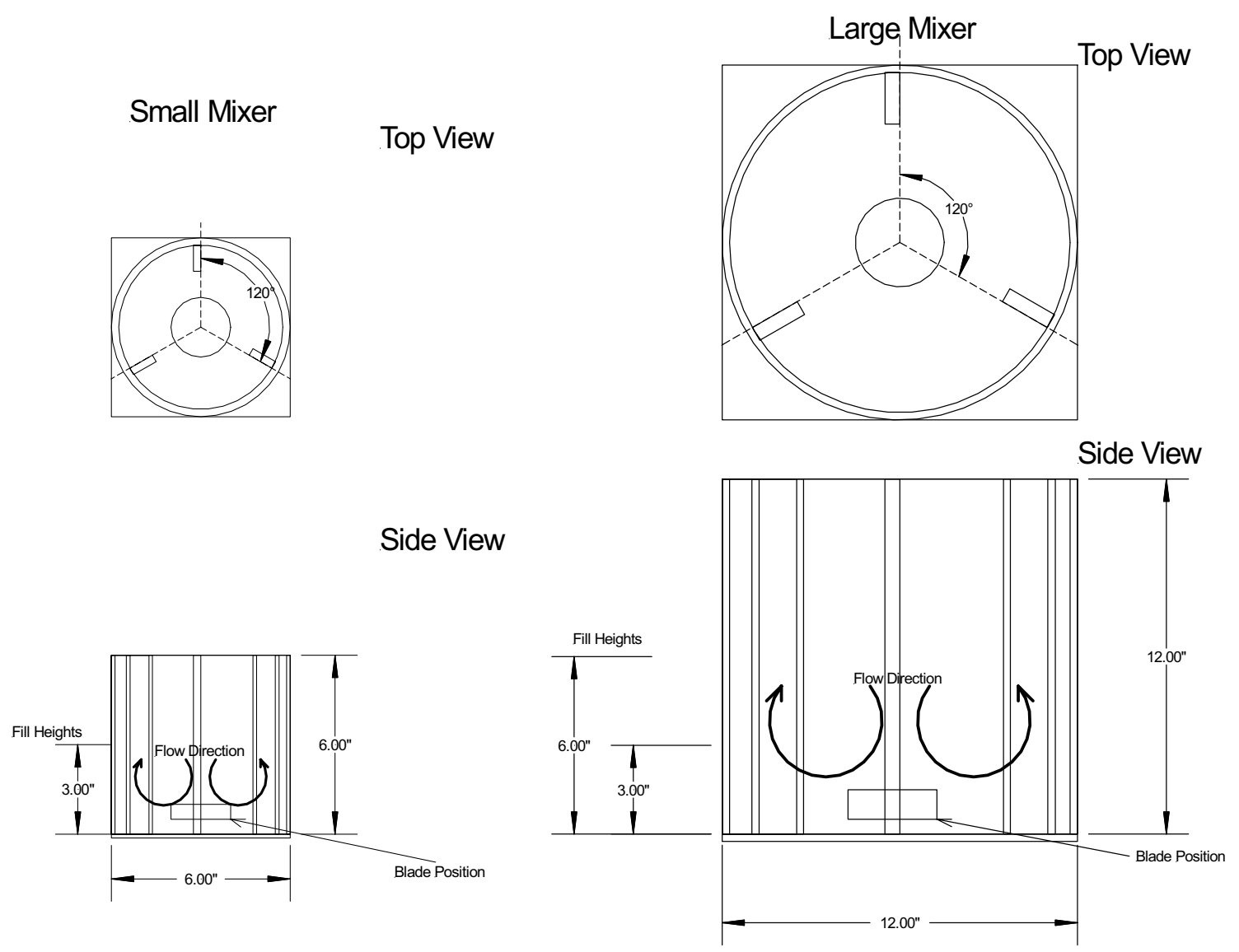

Figure 1. Schematic diagrams of small and large mixing baths for zeolite/iron/surfactant coating of glass foam.

The final mixing bath designs used three solid acrylic baffle plates placed symmetrically around the circumference of the bath container. The dimensions of the baffle plates used in the small mixing bath were $150-\mathrm{mm}(6-\mathrm{in})$ long by $25-\mathrm{mm}$ (1-in) wide by $6.3-\mathrm{mm}(0.25$-in) thick. The large mixing bath contained baffle plates that were $300-\mathrm{mm}$ (12-in) long by $50-\mathrm{mm}(2$-in) wide by $13-\mathrm{mm}$ ( 0.5 -in) thick. Positioning of the baffles and their impact on the flow dynamics is shown in the side views of Figure 1.

A three-blade stainless steel propeller with a total diameter of $75 \mathrm{~mm}$ (3 in) placed on an 8-mm (5/16-in)-diameter, 300-mm (12-in)-long spindle was found to produce the best 
agitation results. Other designs tested included single flat blade paddles and propellers with two blades at various angles. A photograph of the propeller is shown in Figure 2.

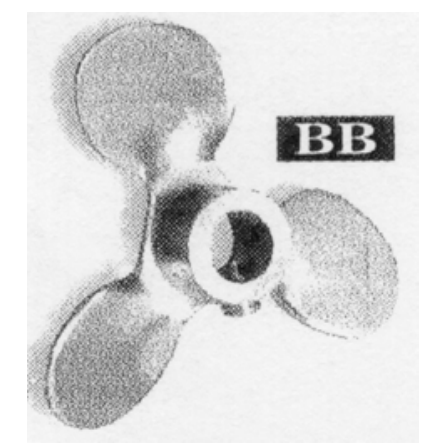

Figure 2. Photograph of the propeller used in the small and large mixing baths.

Scale-up issues were considered during mixer optimization in consultation with Chemineer, Inc. of Dayton, $\mathrm{OH}$. Chemineer is a manufacturer of large industrial mixers. The final mixing process was designed to be adaptable to larger scale production of coated glass foam. Early dipping of the smaller sized glass foam substrate was done in the small mixer. The large bath was used for coating the $230-\mathrm{mm}$-square foam slabs used for bulk production of SMZ/ZVI pellets.

Once the mixing geometry was optimized, the actual amounts of zeolite, iron, surfactant, and water to be used in the mixers were determined. Based on preliminary experiments at NMT aimed at optimizing PCE reduction, the combination of materials listed in Table 2, known as the "batch formulation," was used. Due to a miscommunication, the mass of Carsoquat CT-429 in Table 2 was half of that specified by NMT. This sub-optimal surfactant proportion was not discovered until full-scale pellet manufacture had been completed and the pellets had been shipped to OGI. The implications of the low surfactant loading are considered in the Results and Discussion section.

Table 2. Batch formulation of ingredients used in mixing baths for glass foam coating.

\begin{tabular}{cc}
\hline Material & Weight/Volume \\
\hline Zeolite & 1218.75 grams \\
Iron & 3656.25 grams \\
Carsoquat CT-429 & 182.25 grams \\
Water & $2474.00 \mathrm{~mL}$ \\
\hline
\end{tabular}

\section{Bulk Production of SMZ/ZVI Pellets}

With the routine delivery of the $230-\mathrm{mm}$-square pieces by Cercona, the full-scale production process began. The large mixing bath (Figure 1) was used exclusively at this point. The optimum stirring action was obtained when the blade propeller was placed $13 \mathrm{~mm}$ $(1 / 2$ in) from the bottom of the container and a spindle speed of 900 revolutions per minute 
was used. The spindle was placed slightly off-center in the bath to facilitate dipping of the foam slabs. A typical production run consisted of approximately 575 square slabs, the amount of material that Cercona could supply with one material order.

The bulk production process consisted of coating, drying, and breaking the glass foam slabs. The process is illustrated schematically in Figure 3. Each step of the process is described in detail below.

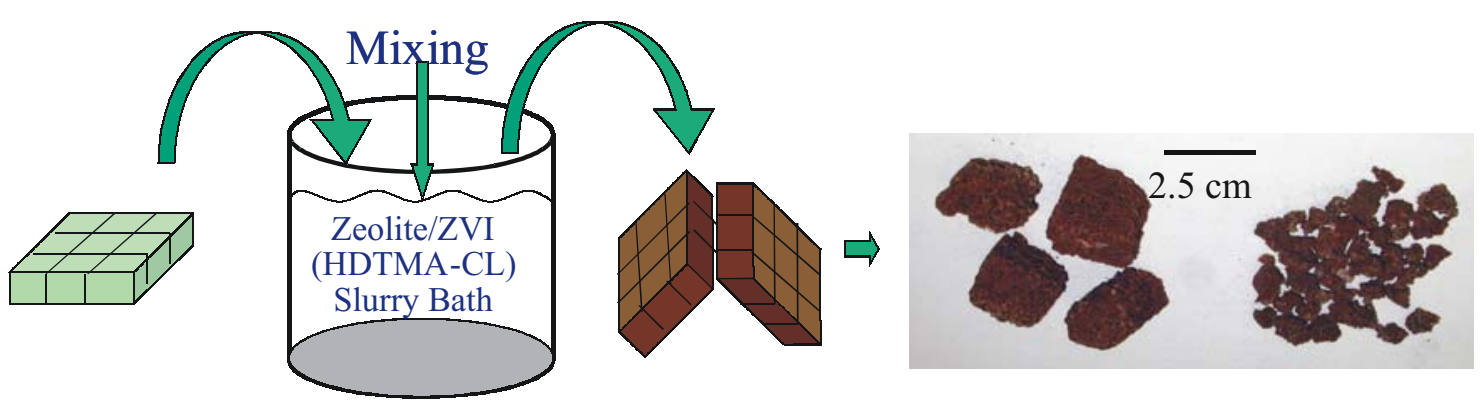

\section{Foam Slab $\rightarrow$ Coating $\rightarrow$ Drying $\quad \rightarrow \quad$ Breaking}

Figure 3. Schematic diagram of the bulk production process for SMZ/ZVI pellets.

\section{Coating}

The mixing process began by combining two batch formulations of raw materials (Table 2) in the large mixing bath (Figure 1), filling the bath approximately half way. Raw materials for up to fifteen batches were pre-weighed and placed in separate containers. Material batches were added to the bath to maintain the slurry level during the dipping process. The foam slabs were placed into the slurry bath by hand and rotated such that all surfaces came in contact with the slurry. The total residence time of each slab in the bath was approximately $5 \mathrm{sec}$. Upon removal, the slab was held above the bath for another $5 \mathrm{sec}$ to allow excess slurry to drip back into the bath. Slabs were then immediately moved to a drying table.

An assembly line procedure was established to streamline production. One person fed slabs to a second person who did the dipping and draining. A third person moved the dipped pieces to the drying table. When the slurry was depleted to a point that it became difficult to coat all surfaces of the slab, an additional batch formulation was added to the mixer in the order water, surfactant, zeolite, and iron. After allowing a few minutes for the ingredients to mix and homogenize in the bath, the dipping process continued. In the later stages of production, the zeolite and iron were premixed in dry form prior to addition to the mixer.

\section{Drying}

Slabs were placed on end and balanced in a "house of cards" fashion. A dehumidifier and electric fan were used to speed drying. The drying process generated heat, presumably due to iron oxidation. For this reason, it was important to ensure that pieces were completely dry before being placed into any closed containers. The drying pellets also exhibited a characteristic surfactant odor. Drying generally required about four days, longer if the heat and humidity in the drying area were not controlled. 


\section{Breaking}

When completely dry, the slabs were ready for breaking into cubes. Breaking was done by hand. A slab was first snapped in two along the grooves and then broken further until a single row of cubes remained. Then the cubes were broken off individually and placed directly into a plastic drum for shipping. Heavyweight gloves were required for hand protection. Safety glasses were also used as the process generated considerable dust and sometimes produced small chips of material. Full drums were then closed and placed in storage until the entire order was complete and ready for shipment to OGI. In general, the breaking process was very successful in producing regular 25-mm-cube shapes. This was particularly true with the slabs that were pre-slotted by Cercona.

The entire production process of dipping, drying, and breaking typically took one full week for each production run. One production run typically generated approximately two full 210 -L (55-gallon) barrels. A total of 64 full barrels were produced during the course of this effort and ultimately delivered to OGI.

Foam cubes were weighed before and after processing to determine the mass fraction of each cube component. The mass fractions of the coating components were based on the batch formulation and the assumption that all of the HDTMA-Cl (30\% of Carsoquat CT-429 by weight) was sorbed by the zeolite. The mass composition of the cubes is shown in Table 3.

Table 3. Mass Composition of SMZ/ZVI pellets bulk-produced at UDRI.

\begin{tabular}{cc}
\hline Cube Component & Mass Fraction \\
\hline Cell-Pore Foam & $34 \%$ \\
Iron & $49 \%$ \\
Zeolite & $16 \%$ \\
HDTMA-Cl & $0.7 \%$ \\
\hline
\end{tabular}

\section{Laboratory Testing of Bulk-Produced SMZ/ZVI Pellets}

\section{Pellet Preparation}

For the laboratory experiments, a separate batch of surfactant-free pellets was prepared by UDRI using a procedure similar to that described above. The masses of zeolite, iron, and water in the batch formulation were the same as in Table 2. After dipping, the dried slabs were broken into $25-\mathrm{mm}$ cubes. The final cubes consisted of approximately $16.5 \%$ zeolite, $49.5 \%$ iron, and $34.0 \%$ glass foam substrate by weight (determined from the mass fraction $(34 \%)$ of the glass foam substrate and the mass ratio (1:3) of the zeolite to the ZVI in the slurry). For laboratory column experiments, these zeolite/ZVI cubes were crushed to smaller pellets (5-10 $\mathrm{mm}$ in one dimension) using a hammer and a screwdriver. During the crushing process about $50 \%$ of the zeolite/ZVI coating was lost, making the final composition of the crushed pellets approximately $12.5 \%$ zeolite, $37.5 \%$ iron, and $50 \%$ glass foam substrate by weight. 


\section{Column Setup}

CHROMAFLEX ${ }^{\mathrm{TM}}$ glass chromatograph columns (Kontes, Vineland, NJ), 300-mm (12-in) long by 48 -mm (1.8-in) diameter, were used in the transport experiments. Column end caps and most of the fittings and tubing were made of Teflon ${ }^{\circledR}$. Glass and Teflon ${ }^{\circledR}$ were chosen because of their limited sorption for chlorinated hydrocarbons. Each end cap was fitted with a three-way polycarbonate valve for influent and effluent sampling. The fluid delivery system consisted of a PHD 2000 programmable multi-channel syringe pump (Harvard Apparatus, Holliston, MA) fitted with 10-mL glass gastight syringes (Hamilton, Reno, NV) and fed from a 60-L collapsible Teflon ${ }^{\circledR}$ bag (Lab Safety Supply, Janesville, WI).

All experiments were performed at $22.0 \pm 1.0^{\circ} \mathrm{C}$. Four columns were packed with crushed pellets, purged with $\mathrm{CO}_{2}$ for $1.5 \mathrm{hr}$ to promote water saturation and neutralization of excess base from the silica foam, then fed with degassed synthetic OGI water $\left(0.52 \mathrm{mM} \mathrm{NaHCO}_{3}\right.$, $0.08 \mathrm{mM} \mathrm{MgSO}_{4}, 0.09 \mathrm{mM} \mathrm{CaCl}_{2}, 0.01 \mathrm{mM} \mathrm{KNO}_{3}, 0.12 \mathrm{mM} \mathrm{CaCO}_{3}$, and $0.02 \mathrm{mM}$ $\left.\mathrm{Mg}\left(\mathrm{NO}_{3}\right)_{2}\right)$ at a linear velocity of $0.5 \mathrm{~m} \mathrm{~d}^{-1}$. This synthetic water was used as the aqueous matrix for all subsequent laboratory experiments. All injections were conducted in an upward flow mode. The weight of each column was determined approximately every pore volume $(\mathrm{PV})$. When the weight difference between two consecutive measurements was less than $0.2 \%$, a column was considered fully saturated, and the porosity of the packed pellets was determined by the difference between the saturated weight and the dry weight of the column. The bulk density of the packed pellets was calculated based on the dry mass of the packed pellets and the volume of the column.

\section{Surfactant Modification}

After all four columns were fully water-saturated, 10.0-mM HDTMA-Cl solution (prepared from $25 \%$ by weight aqueous HDTMA-Cl, Aldrich Chemical Company, Milwaukee, WI) was fed into two columns at a linear velocity of $0.5 \mathrm{~m} \mathrm{~d}^{-1}$ to surfactantmodify the pellets, and the effluent HDTMA concentrations were monitored. The sorption of HDTMA by the zeolite/ZVI pellets reached equilibrium after $10 \mathrm{PV}$ of injection, as indicated by the constant effluent HDTMA concentration. Surfactant-free synthetic OGI water was then injected at the same flow rate to rinse nonsorbed surfactant from the system. After $10 \mathrm{PV}$ of rinsing the effluent HDTMA concentration reached a constant value below the critical micelle concentration. The final HDTMA loadings for these two surfactant-modified columns, SM1 and SM2, were 13.3 and $15.3 \mathrm{mmol} \mathrm{kg}^{-1}$, respectively. During the surfactant loading of columns SM1 and SM2, the two unmodified columns, UM1 and UM2, received surfactant-free water at the same flow rate.

\section{Transport Experiments}

PCE $(12.0 \mu \mathrm{M})$ sorption/reduction in the SM and UM columns was determined at three different flow rates: $0.49 \pm 0.02,0.97 \pm 0.05$, or $1.89 \pm 0.09 \mathrm{~m} \mathrm{~d}^{-1}$. For each experiment, the effluent concentrations of PCE and its daughter products (TCE, 1,1-DCE, trans-DCE, cisDCE, and vinyl chloride (VC)) were monitored. A step injection of about 10 PV was used for each PCE transport experiment. In between each separate experiment the columns were flushed with contaminant-free water until the effluent concentrations of the chlorinated ethylenes reached nondetectable levels. 
Six-milliliter effluent samples were collected every $0.15-0.20$ PV by attaching $10-\mathrm{mL}$ Hamilton gastight syringes to the effluent sampling points and switching the 3-way valves. The samples were immediately transferred to $10-\mathrm{mL}$ glass headspace vials and capped with Teflon ${ }^{\circledR}$-lined butyl septa. Separate effluent samples for $\mathrm{pH}$ determination were collected in the same manner every $0.5 \mathrm{PV}$. Influent samples were collected every pore volume to determine input concentrations. Flow rates were determined from the cumulative volume of effluent over time.

Separate transport experiments with the conservative tracer tritiated water were conducted at the low and high flow rates to determine the longitudinal dispersivity $\left(\alpha_{L}\right)$ values of the packed pellets. A 1-PV pulse of tritiated water $\left(11,800\right.$ counts $\left.\mathrm{min}^{-1} \mathrm{~mL}^{-1}\right)$ was injected, and effluent samples were collected using Retriever II fraction collectors (ISCO Inc., Lincoln, $\mathrm{NE})$.

\section{Methods of Analysis}

PCE, TCE, 1,1-DCE, trans-DCE, cis-DCE, and VC were analyzed using a HewlettPackard 5890 gas chromatograph equipped with a $0.53-\mathrm{mm}$ by $30-\mathrm{m}$ GSQ-PLOT capillary column (J\&W Scientific, Folsom, CA) and a flame ionization detector (FID). Helium was used as the carrier gas with a flow rate of $15 \mathrm{~mL} \mathrm{~min}^{-1}$. A Hewlett-Packard 7694 headspace autosampler was used for sample injection. The samples in the headspace vials were equilibrated at $60{ }^{\circ} \mathrm{C}$ for $30 \mathrm{~min}$ with vigorous shaking. The gaseous sample was injected splitless at $210^{\circ} \mathrm{C}$, and was detected by the FID at $240{ }^{\circ} \mathrm{C}$. The oven temperature program profile was $50{ }^{\circ} \mathrm{C}$ for $2 \mathrm{~min}$, ramp $30^{\circ} \mathrm{C} \mathrm{min}{ }^{-1}$ to $180{ }^{\circ} \mathrm{C}$, and hold at $180{ }^{\circ} \mathrm{C}$ for $8 \mathrm{~min}$. Calibration curves were produced using standards obtained from Supelco (Bellefonte, PA). The detection limits of this method for PCE, TCE, three DCE isomers, and VC were 0.016, $0.01,0.005$, and $0.006 \mu \mathrm{M}$, respectively. The linear response ranges for PCE, TCE, three DCE isomers, and VC were up to $15,15,10$, and $8 \mu \mathrm{M}$, respectively.

HDTMA was analyzed via high performance liquid chromatography using the method of Li and Bowman (1997). Tritium was analyzed by liquid scintillation counting (Beckman LS 6500, Palo Alto, CA) after mixing $1 \mathrm{~mL}$ of the effluent sample with $5 \mathrm{~mL}$ of Ecolite ${ }^{+}$ scintillation cocktail (ICN Biomedical, Costa Mesa, CA). Solution pH was measured using a Beckman $\Phi 45 \mathrm{pH}$ meter with a Beckman combination $\mathrm{pH}$ electrode. The $\mathrm{pH}$ electrode was calibrated daily. Hydraulic conductivity of the pellets was measured using a constant head method. Sixteen well-shaped cubes were used to estimate the internal porosity (intra-pellet porosity). The internal porosity of the pellets was determined as the difference between the total cube volume (calculated from the dimensions) and the volume of solids (determined from the volume of water displaced by the cubes after saturation).

\section{Transport Model}

The numerical model HYDRUS-1D version 2.0 (Šimunek et al. 1998) was used to simulate PCE breakthrough curves. The following partial differential equation was used to describe the one-dimensional transport of a solute undergoing reversible sorption and first order decay in porous media:

$$
\frac{\partial C}{\partial t}+\frac{\rho_{b}}{\theta} \frac{\partial S}{\partial t}=D \frac{\partial^{2} C}{\partial x^{2}}-v \frac{\partial C}{\partial x}-\mu_{L} C-\frac{\rho_{b}}{\theta} \mu_{S} S
$$


where $C$ is the solute concentration in aqueous phase, $S$ is the solute concentration on solid phase, $t$ is time, $\rho_{b}$ is the sediment bulk density, $\theta$ is the porosity, $D$ is the hydrodynamic dispersion coefficient, $v$ is the travel velocity, $x$ is distance, $\mu_{L}$ is the aqueous phase first order decay constant, and $\mu_{S}$ is the solid phase first order decay constant.

Previous studies indicated that the sorption of PCE and other non-polar organics by SMZ followed a linear sorption isotherm (Bowman et al. 1995; Li and Bowman 1998):

$$
S=K_{d} C
$$

where $K_{d}$ is the distribution coefficient. Coupling Eq. (1) with the linear sorption isotherm yields:

$$
\left(1+\frac{\rho_{b}}{\theta} K_{d}\right) \frac{\partial C}{\partial t}=D \frac{\partial^{2} C}{\partial x^{2}}-v \frac{\partial C}{\partial x}-\mu_{T} C
$$

where $\mu_{T}$ is the overall first order reaction rate constant given by

$$
\mu_{T}=\left(\mu_{L}+\frac{\rho_{b} K_{d}}{\theta} \mu_{S}\right)
$$

Parameter values were estimated using Eq. (3) with least-squares parameter optimization (Šimunek et al. 1998). For the tritium tracer, $K_{d}, \mu_{L}$, and $\mu_{S}$ were set to 0 , and the longitudinal dispersivity ( $\alpha_{L}=D / v$ while neglecting molecular diffusion) values for each column at both low and high flow rates were determined. For PCE, the dispersivity values from the tritium tests were used, and the values of $K_{d}$ and $\mu_{T}$ were estimated. The overall first-order degradation constant $\mu_{T}$ was evaluated since $\mu_{L}$ and $\mu_{S}$ cannot be uniquely determined from inverse modeling of the data.

\section{Pilot Test of the SMZ/ZVI Permeable Barrier Physical Model Configuration}

Pilot-scale experiments were conducted in the OGI Large Experimental Aquifer Program PRB pilot-scale testing facility. A complete description of the facility is presented in the Phase II Topical Report (Bowman et al. 1999). Critical details of the pilot-test facility are summarized below.

The pilot-test tank consists of a concrete bunker lined with a steel bunker. Between the two bunkers is an annular space filled with pea gravel. The annular space can be monitored for leaks from the inner steel bunker. The inside of the steel bunker is lined with geotextile and 2.5-mm (0.1-in)-thick high-density polyethylene (HDPE).

The overall dimensions of the pilot-test tank are $8.5-\mathrm{m}$ (28-ft) wide by $8.5-\mathrm{m}(28-\mathrm{ft})$ long by $3-\mathrm{m}(10-\mathrm{ft})$ deep. The tank is located below the ground surface and is enclosed by a metal building with walls on two sides.

A large frame for containing the permeable reactive barrier material is located within the tank. It consists of epoxy-painted steel and has overall dimensions of 2-m (6.6-ft) deep by $1-\mathrm{m}(3.3-\mathrm{ft})$ thick by $6-\mathrm{m}(19.6-\mathrm{ft})$ long. It is divided into three $2-\mathrm{m}(6.6-\mathrm{ft})$ sections. The bottom and ends of each section are solid metal, while the upgradient and downgradient faces of the barrier are perforated metal with $\sim 3$ - $\mathrm{mm}(1 / 8$-in)-diameter openings and a total porosity of $\sim 50 \%$. The location of the barrier sections can be seen in Figure 4. 
(a)

Horizontal

Plane

(b)

Vertical

Plane
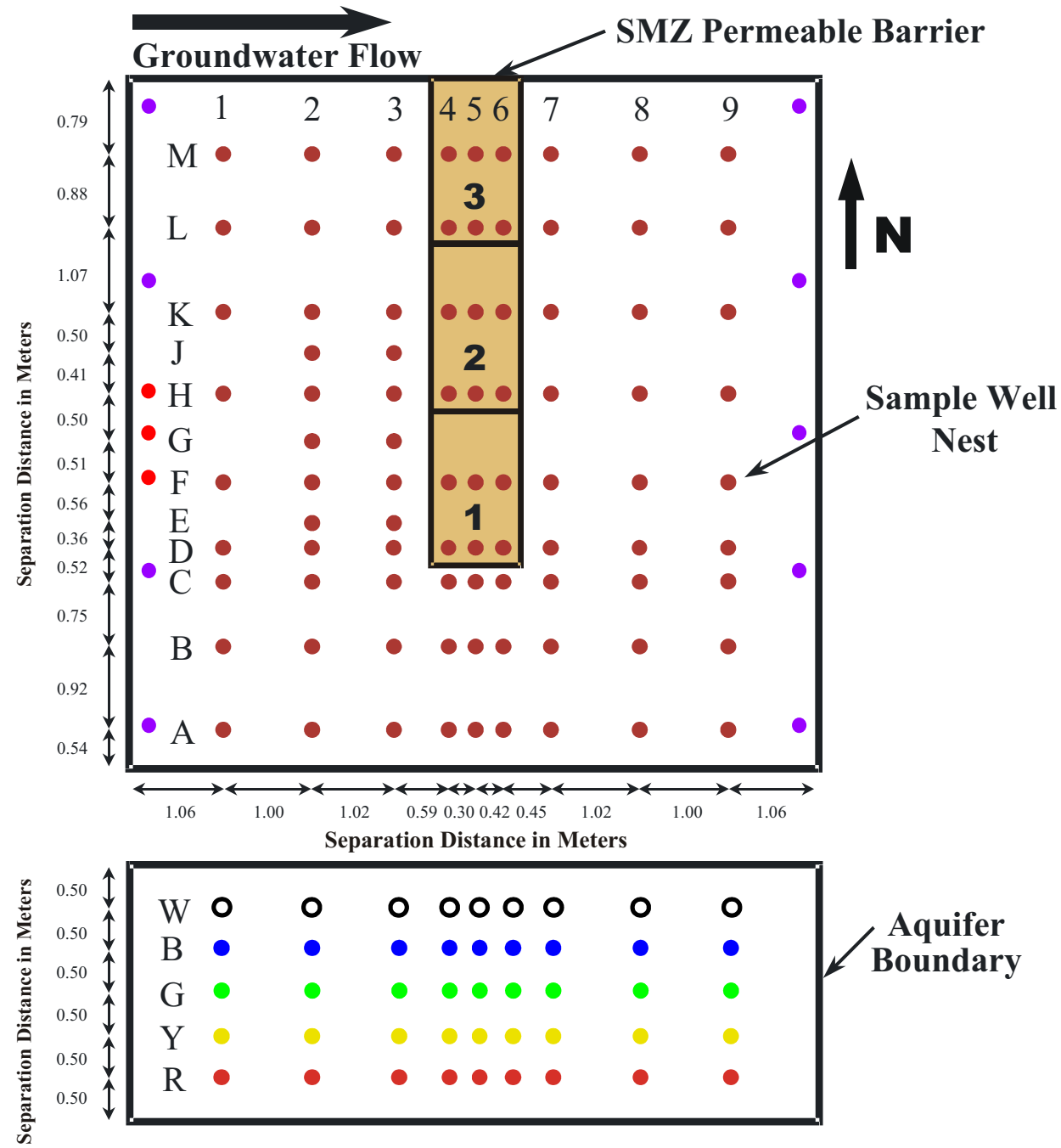

Figure 4. Plan and cross-section views of the PRB pilot-test facility. Brown circles are sampling locations, purple circles are injection and extraction well locations, and red circles are contaminant injection locations. Groundwater flow is from left to right.

The tank outside of the PRB frame is filled with medium beach sand (hydraulic conductivity $=5 \times 10^{-4} \mathrm{~m} \mathrm{~s}^{-1}$ ). For the current experiment, the northern barrier section (cell 3 in Figure 4) was filled with the same medium sand used in the rest of the model. The other two barrier sections (cells 1 and 2) were filled with SMZ/ZVI cubes. Pea gravel was emplaced in the barrier annular space between the sand and the cubes.

\section{Flow Control System and Sampling Array}

Groundwater flow through the model is controlled by injection and extraction of groundwater from wells located at either end of the physical model. The injection system consists of 12 wells, five of which are screened between 1.5 and $3 \mathrm{~m}(5.0$ and $10 \mathrm{ft})$ below ground surface and seven of which are screened from near ground surface to $1.5 \mathrm{~m}(5.0 \mathrm{ft})$. These wells are generally evenly spaced across the model (about 1.8-m (6.0 ft) apart); however, three of the shallow wells were spaced more closely together and were used for injection of the contaminants (Figure 4). 
The groundwater-sampling network in the physical model consists of 435 discrete sampling points. About 120 of those points were used for this study. Each sampling location consists of a section of quarter-inch HDPE tubing with nylon screen covering the belowground end of the tube and a dedicated piece of Viton peristaltic pump tubing at the aboveground end. Plan and section views of the sampling network of the PRB facility are shown in Figure 4 . The coordinates of the individual samplers are specified in Table 4.

Table 4. Locations of multi-level samplers in the pilot-test tank. Distances measured from origin at bottom SW corner of tank. Barrier extends from $(3.47,2.26,1.00)$ to $(4.47,8.26,3.00)$.

\begin{tabular}{cccccc}
\hline $\begin{array}{c}\text { Column } \\
\text { Location }\end{array}$ & X(m) & Row Location & Y(m) & Height & Z(m) \\
\hline 1 & 1.06 & $\mathrm{~A}$ & 0.54 & $\mathrm{R}$ & 0.50 \\
2 & 2.06 & $\mathrm{~B}$ & 1.46 & $\mathrm{Y}$ & 1.00 \\
3 & 3.08 & $\mathrm{C}$ & 2.21 & $\mathrm{G}$ & 1.50 \\
\hline 4 & 3.67 & $\mathrm{D}$ & 2.73 & $\mathrm{~B}$ & 2.00 \\
5 & 3.97 & $\mathrm{E}$ & 3.09 & $\mathrm{~W}$ & 2.50 \\
6 & 4.39 & $\mathrm{~F}$ & 3.65 & & \\
7 & 4.84 & $\mathrm{G}$ & 4.16 & & \\
8 & 5.86 & $\mathrm{H}$ & 4.66 & & \\
9 & 6.86 & $\mathrm{~J}$ & 5.07 & & \\
\hline & & $\mathrm{K}$ & 5.57 & & \\
& & $\mathrm{~L}$ & 6.64 & & \\
\hline
\end{tabular}

\section{Preparation for Contaminant Injection and Sampling}

The entire test tank was slowly saturated with water and simulated groundwater flow was initiated. Measurements of water samples within and downgradient of the barrier showed $\mathrm{pHs}$ in excess of 9, presumably due to leaching of excess base from the glass foam cube cores. Laboratory experiments at NMT had confirmed that the PCE reduction capabilities of the pellets were adversely affected above $\mathrm{pH} 9$.

In order to improve the performance of the barrier an attempt was made to neutralize the residual base of the cubes. Based on the laboratory column experiments at NMT, it was concluded that either flushing with pure carbon dioxide or a saturated carbon dioxide solution could neutralize the cubes. Therefore, the pilot-test tank was drained and the PRB was drained and flushed with pure carbon dioxide. Carbon dioxide provided by six standard 2200-psi cylinders was flushed through the barrier over the course of several days. When the barrier was re-saturated and flushed, the $\mathrm{pH}$ in both cases remained fairly high ( 9). This may have been due to poor exchange of the carbon dioxide with the cubes because the internal porosity of the cubes may still have been nearly saturated with water. Subsequent attempts to neutralize excess base by circulating hydrochloric acid solution through the PRB likewise failed to significantly lower the $\mathrm{pH}$. It was concluded that further neutralization in situ was not practical, and evaluation of the existing barrier proceeded. 


\section{Contaminant Injection, Sampling, and Analyses}

Groundwater flow, without contaminant introduction, was initiated in June 2001. The flow rate into each well (i.e., each of the nine regular wells as well as the sum of the three contaminant-injection wells) was $300 \mathrm{~mL} \mathrm{~min}^{-1}$. The total flow rate into the model was, therefore:

$$
\text { Total flow }=300 \mathrm{~mL} \mathrm{~min} \operatorname{mon}^{-1} 10 \text { injection wells }=3000 \mathrm{~mL} \mathrm{~min}^{-1}=4.32 \mathrm{~m}^{3} \mathrm{~d}^{-1}
$$

With a porosity of 0.35 , an overall saturated thickness of $3 \mathrm{~m}$, and a width of $8.5 \mathrm{~m}$, the groundwater velocity was about $0.5 \mathrm{~m} \mathrm{~d}^{-1}$.

A well-defined contaminant source configuration with a known, constant concentration was produced upgradient from the PRB and allowed to flow downgradient through the PRB. Contaminants were pumped from stock solutions using ceramic piston pumps. The metered stock solutions were mixed with city water flowing at a rate of $300 \mathrm{~mL} \mathrm{~min}{ }^{-1}$ (i.e., equivalent to the volume of water flowing into each well). The mixture was then split to three flow meters, which were valved to provide equal flow to each of the three shallow injection wells. The flow system is shown schematically in Figure 5 and in photographs in Figures 6-8.

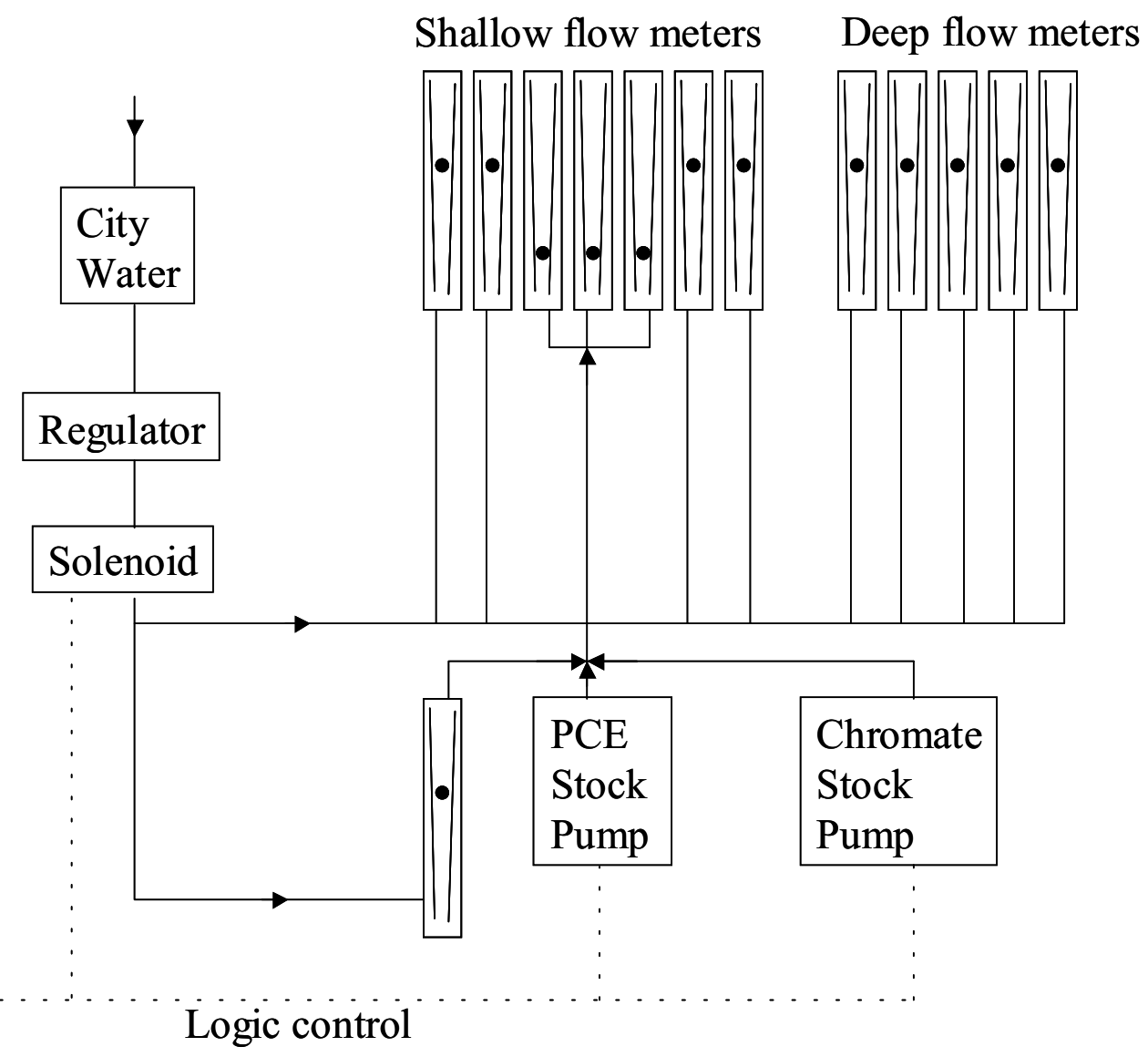

Figure 5. Schematic drawing of the injection control system showing both the groundwater flow control and contaminant injection control. 


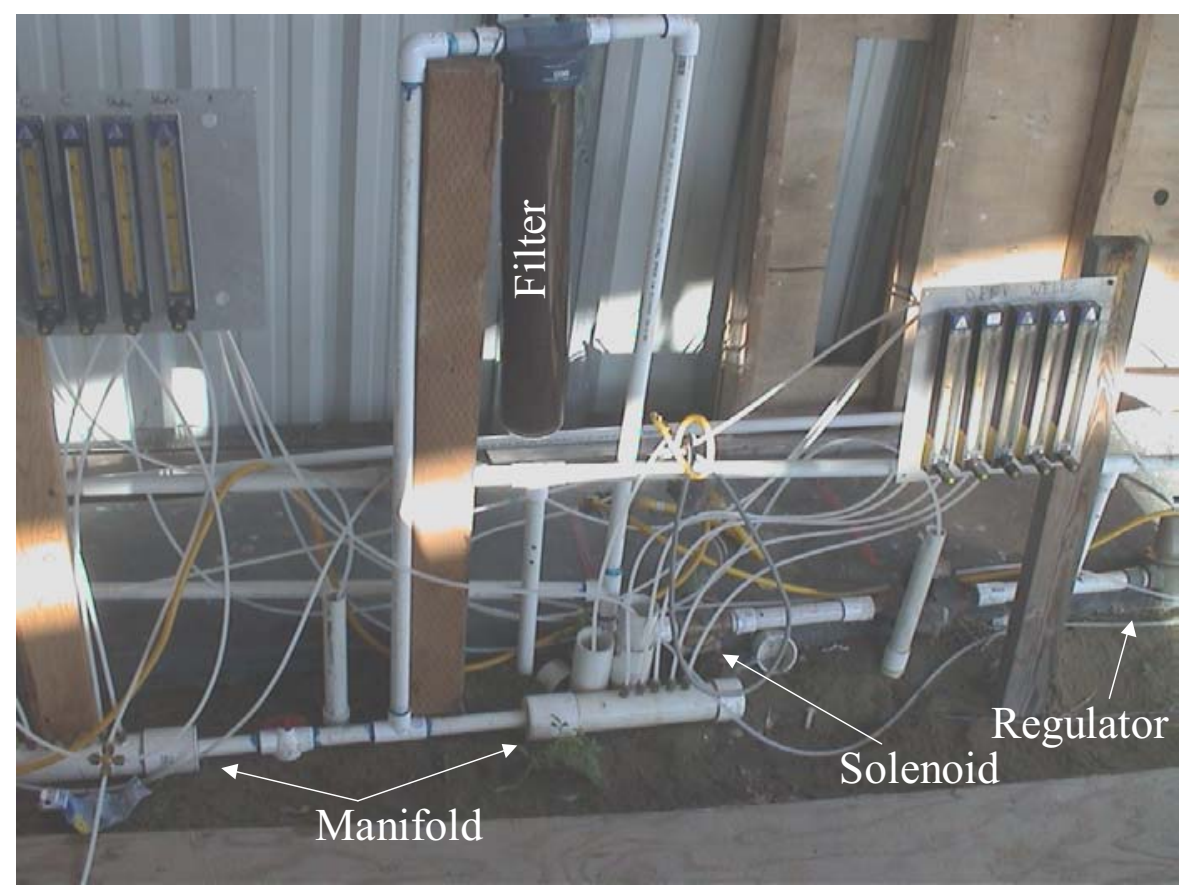

Figure 6. Photograph of the groundwater injection control system.

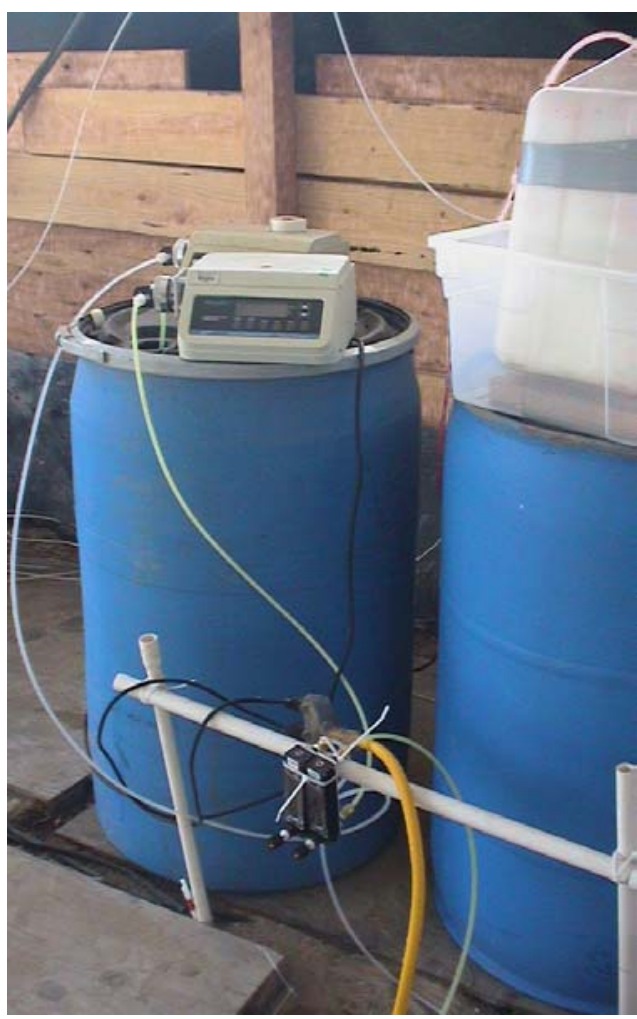

Figure 7. Photograph of the contaminant injection system.

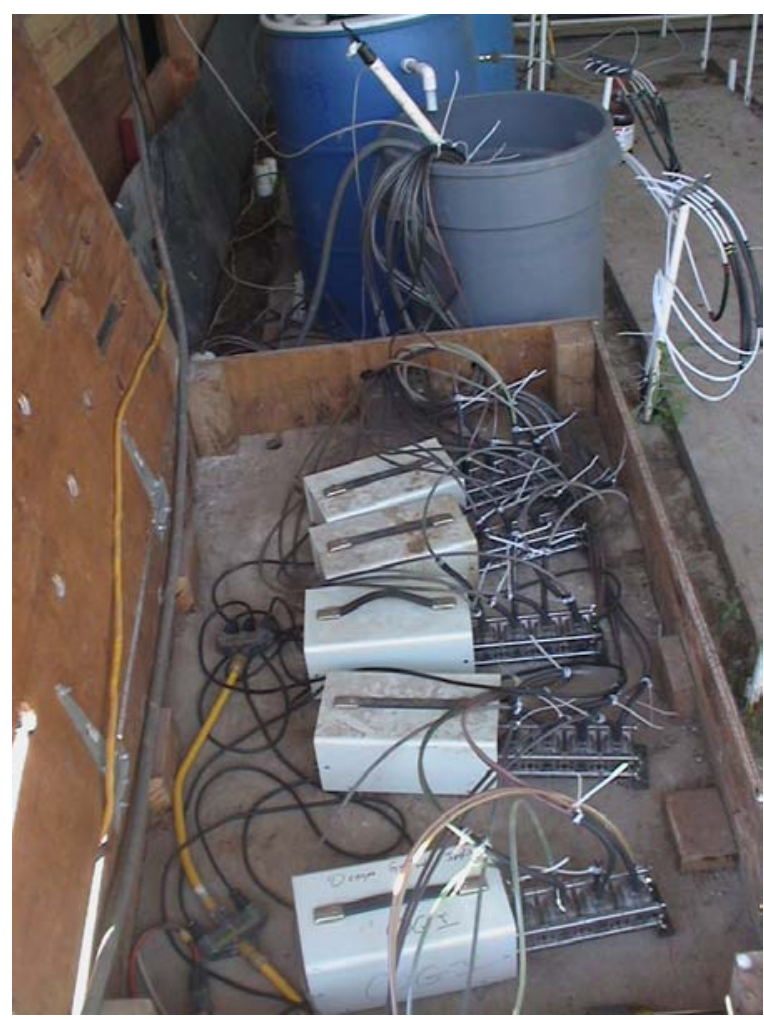

Figure 8. Photograph of the groundwater extraction pumps. 
Background PCE samples were collected in June 2001 prior to contaminant injection. In all cases, PCE and dechlorination product concentrations were less than $10 \mu \mathrm{g} \mathrm{L}^{-1}$.

PCE injection was initiated on 26 June and chromate injection was initiated on 29 June 2001. Target concentrations for the contaminants were $1000 \mu \mathrm{g} \mathrm{L}^{-1}$ for PCE and $10 \mathrm{mg} \mathrm{L}^{-1}$ chromate. As shown below, actual observed maximum concentrations in the physical model were on the order of $500 \mu \mathrm{g} \mathrm{L}^{-1}$ for PCE and $6 \mathrm{mg} \mathrm{L}^{-1}$ for chromate.

Weekly sampling of transects $\mathrm{F}$ and $\mathrm{H}$ along the flow path (Figure 4), as well as sampling of two transects perpendicular to groundwater flow, were carried out during the study. Samples were collected by overfilling 40-mL VOA vials and eliminating all headspace. PCE and dechlorination products were analyzed by headspace GC, using two detectors (electron capture and flame ionization) to allow simultaneous analysis over the entire expected concentration range $\left(0.1-1000 \mu \mathrm{g} \mathrm{L}^{-1}\right)$. Chromate analyses were performed using HPLC. Further details on the analytical procedures and detection limits are provided in the Phase 2 Topical Report (Bowman et al. 1999). 


\section{Results and Discussion}

\section{Laboratory Testing of Bulk-Produced SMZ/ZVI Pellets}

\section{Pellet Properties}

The BET surface area of the pellets was $28.2 \mathrm{~m}^{2} \mathrm{~g}^{-1}$, indicating that the thin layer of SMZ/ZVI coating maintained the high surface area of the SMZ and ZVI powders. The iron rust $\left(40.3 \mathrm{~m}^{2} \mathrm{~g}^{-1}\right)$ on the pellets likely contributed to this high surface area. The columns packed with the crushed pellets had a very high porosity $(0.81-0.82)$ and a very low bulk density $\left(0.66-0.67 \mathrm{~g} \mathrm{~cm}^{-3}\right)$. The internal porosity (intra-pellet porosity) of the pellets was 0.4 , approximately $50 \%$ of the total porosity. The hydraulic conductivity of the crushed pellets was $0.097 \mathrm{~m} \mathrm{~s}^{-1}$; the original larger pellets $(25-\mathrm{mm}$ cubes) would have an even higher hydraulic conductivity. The $\sim 0.1-\mathrm{m} \mathrm{s}^{-1}$ hydraulic conductivity of the pellets is $2-3$ orders of magnitude greater than that of granular ZVI, granular ZVI mixed with coarse sand, or foamed aluminosilicate-bound ZVI pellets (O'Hannesin and Gillham 1998; Puls et al. 1999; Naftz et al. 2000). The pellets also showed excellent mechanical strength, with no physical deterioration evident after passing more than 100 $\mathrm{PV}$ of water through the columns.

\section{PCE Reduction}

The inlet PCE concentration was constant at 11. $0 \pm 0.5 \mu \mathrm{M}$ over the course of the column experiments. This concentration was lower than that in the Teflon ${ }^{\circledR}$ bag reservoir $(12.0 \mu \mathrm{M})$, probably due to sorption of PCE onto the tubing and fittings of the delivery system. For the unmodified columns, PCE effluent concentrations at steady state were about 3.0, 4.0, and $6.0 \mu \mathrm{M}$ at velocities of $0.5,1.0$, and $1.9 \mathrm{~m} \mathrm{~d}^{-1}$, respectively (Figure 9). Steady-state PCE effluent concentrations for the surfactantmodified columns were significantly lower than those for the unmodified columns (i.e., by factors of 7,4 , and 3 at the three flow rates, respectively, Figure 9). Since the inlet PCE concentration, effluent $\mathrm{pH}(9.2 \pm 0.1)$, mass of packed pellets $(362.0 \pm 1.5 \mathrm{~g})$, porosity, and bulk density for the four columns were almost identical, the enhanced PCE reduction by the surfactant-modified pellets was clearly due to the presence of surfactant.
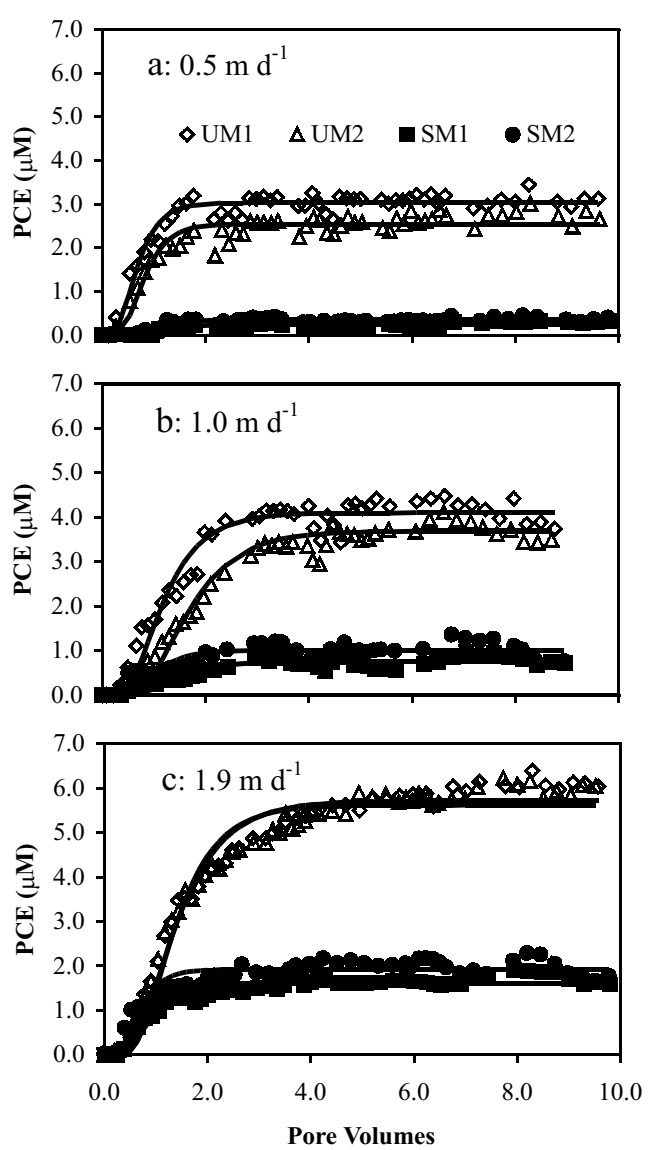

Figure 9. Effluent PCE concentrations during $P C E$ reduction at various flow rates: (a) $0.5 \mathrm{~m} \mathrm{~d}^{-1}$, (b) $1.0 \mathrm{~m} \mathrm{~d}^{-1}$, and (c) $1.9 \mathrm{~m} \mathrm{~d}^{-1}$. The smooth curves are the best-fit simulations using HYDRUS 1-D. Effluent PCE concentrations were significantly lower in the surfactantmodified (SM) columns than in the unmodified (UM) columns.

The enhanced PCE reduction by the SMZ/ZVI pellets observed in this transport study was consistent with the results from an earlier batch study, where enhanced PCE reduction 
(a 3-fold increase in the pseudo-first order reduction rate constant) was achieved using a different formulation of SMZ/ZVI pellets ( $\mathrm{Li}$ et al. 1999). The observed enhancement of PCE reduction by the SMZ/ZVI pellets may be attributed to (1) increased sorption of PCE directly onto iron surfaces by iron-bound HDTMA, accelerating the surface reduction of PCE (Li et al. 1999), and/or (2) an increased local PCE concentration in the vicinity of the iron surface due to the sorption of PCE by SMZ, promoting mass transfer of PCE onto the ZVI surface.

Enhanced PCE reduction was observed when iron was modified with cationic or non-ionic surfactants. For example, Li (1998) observed in a batch study that the PCE reduction rate constant increased by a factor of three when the ZVI (US Metal, $<0.13 \mathrm{~mm}$ ) was modified with the cationic surfactant HDTMA. A recent batch study by Alessi and Li (2001) also showed that PCE reduction rate constants were 4-5 times higher for octyltrimethylammonium (OTMA)-modified ZVI (Fisher Scientific, $<0.13 \mathrm{~mm}$ ), 5-7 times higher for dodecyltrimethylammonium (DDTMA)-modified ZVI, and 12-19 times higher for HDTMAmodified ZVI relative to the unmodified ZVI. Loraine (2001) observed a PCE reduction rate increase of 39\% in batch studies when the ZVI (Fisher Scientific, $0.4 \mathrm{~mm}$ ) was modified with the non-ionic surfactant Triton X-100. Weber (1996) suggested that reduction of organic compounds by ZVI is a surface reaction that requires close contact between the compounds and the iron. For such a reaction, the rate is proportional to the surface concentration of the organic compound (Fogler 1999). Bound cationic or non-ionic surfactants on ZVI may serve as hydrophobic islands for PCE partitioning, resulting in an increased PCE surface concentration on reactive sites. It is thus possible that the enhanced PCE reduction by the SMZ/ZVI pellets was solely due to the HDTMA-modified ZVI, the SMZ serving as a separate sorbent for PCE.

Alternatively, the enhanced PCE reduction by the SMZ/ZVI pellets may be due to the increased local PCE concentration in the vicinity of the iron surface due to the sorption of PCE by SMZ that is in close proximity to the ZVI. The increased local PCE concentration in the vicinity of the iron surface may promote mass transfer and sorption of PCE onto the surface of ZVI, since the diffusive mass flux of a contaminant is proportional to the concentration gradient across the thin mass transfer layer surrounding the solid particle. The enhanced mass transfer may lead to an increased surface reaction rate, especially in systems where mass transfer is the rate-limiting step (Fogler 1999). As discussed below, PCE reduction in both the surfactant-modified and unmodified columns appeared to be masstransfer limited. Therefore, this latter mechanism may be particularly important for enhanced PCE reduction by the SMZ/ZVI pellets.

Whether or not sorption of PCE by SMZ directly contributes to enhanced PCE reduction, the presence of SMZ in the pellets may prolong the performance of the HDTMA-ZVI. Due to the reversible nature of HDTMA sorption onto zeolite and ZVI, the surface-bound HDTMA will slowly leach off of the ZVI in a flow-through system. Since the HDTMA-Cl loading on the zeolite $\left(160 \mathrm{mmol} \mathrm{kg}^{-1}\right)$ is much higher than that on the ZVI $\left(15 \mathrm{mmol} \mathrm{kg}{ }^{-1}\right)$, the SMZ may serve as a reservoir to replenish HDTMA on the ZVI surface.

\section{Daughter Products of PCE Reduction}

TCE was observed in the effluent of the surfactant-modified and unmodified columns during the PCE reduction, with the steady-state concentrations for the surfactant-modified columns $\left(0.2,0.4\right.$, and $0.7 \mu \mathrm{M}$ at velocities of $0.5,1.0$, and $1.9 \mathrm{~m} \mathrm{~d}^{-1}$, respectively) roughly 
10 times higher than for the unmodified columns (Figure 10). No cis-DCE was observed in the effluent of the unmodified columns, whereas cis-DCE was observed in the effluent of the surfactant-modified columns (steady-state concentrations of $0.01,0.02$, and $0.03 \mu \mathrm{M}$ at the three flow rates, respectively, Figure 11). No other daughter products (trans-DCE, 1,1-DCE, and VC) were observed in either unmodified or surfactant-modified columns at any flow rate. The total chlorinated daughter products due to PCE reduction accounted for less than $1 \%$ of the injected PCE for the unmodified columns, and less than $7 \%$ of the input PCE for the surfactant-modified columns at the flow rates examined.
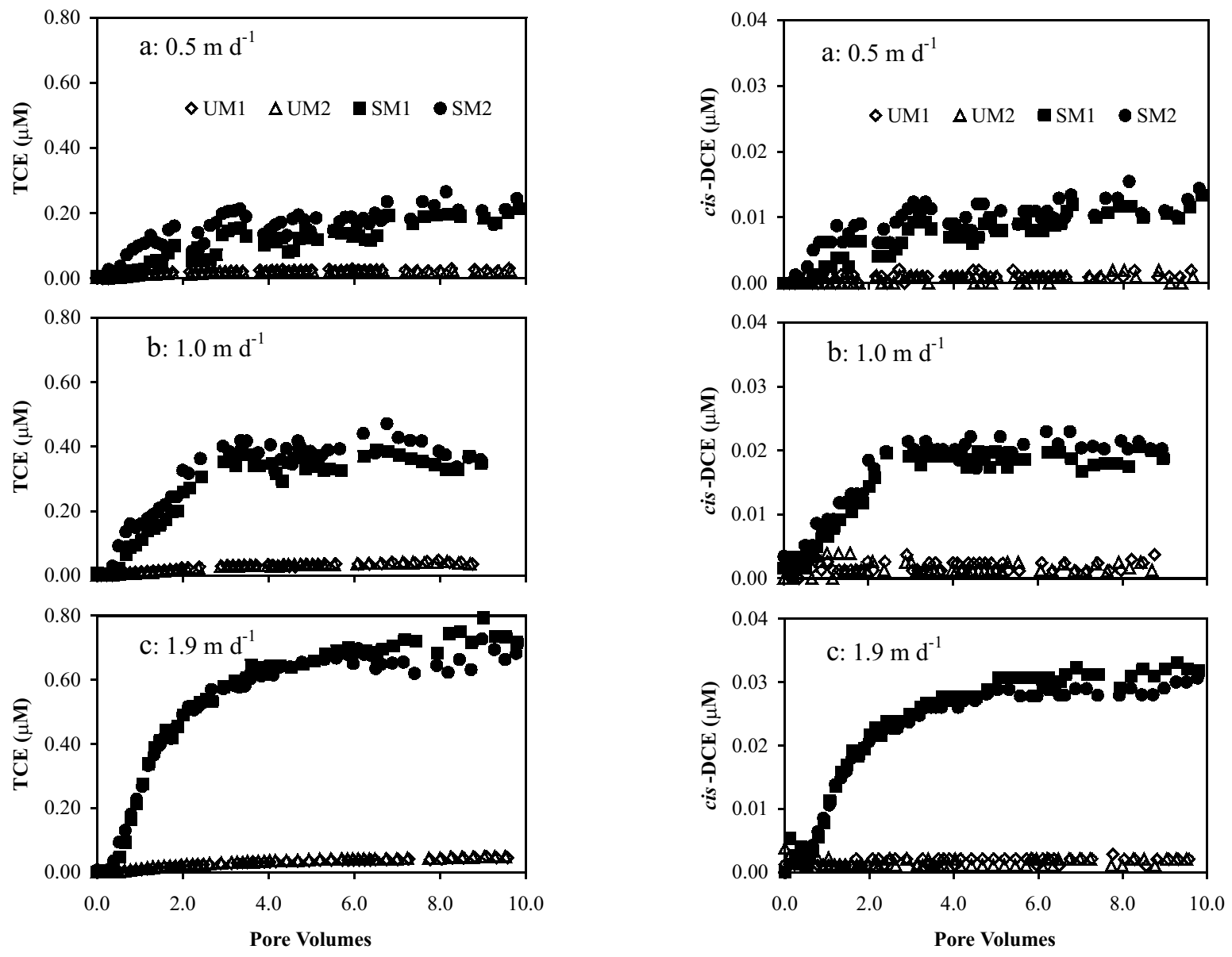

Figure 10. Effluent TCE concentrations during PCE reduction at various flow rates: (a) $0.5 \mathrm{~m} \mathrm{~d}^{-1}$, (b) $1.0 \mathrm{~m} \mathrm{~d}^{-1}$, and (c) $1.9 \mathrm{~m} \mathrm{~d}^{-1}$. TCE production due to PCE reduction was significantly higher in the surfactantmodified (SM) columns than in the unmodified (UM) columns.

Figure 11. Effluent cis-DCE concentrations during PCE reduction at various flow rates: (a) $0.5 \mathrm{~m} \mathrm{~d}^{-1}$, (b) $1.0 \mathrm{~m} \mathrm{~d}^{-1}$, and (c) $1.9 \mathrm{~m} \mathrm{~d}^{-1}$. Cis-DCE generation during PCE reduction was significantly higher in the surfactantmodified (SM) columns than in the unmodified (UM) columns.

Significant increases in TCE accumulation during PCE reduction were observed in batch studies when ZVI was modified with the cationic surfactant HDTMA (Li 1998; Alessi and Li 2001) or with the non-ionic surfactant Triton X-100 (Loraine 2001). In the presence of ZVI (Fisher Scientific, $0.13 \mathrm{~mm}$ ) it was found that $87 \%$ of the PCE underwent reductive $\beta$-elimination to form dichloroacetylene, and less than $10 \%$ of the PCE underwent 
hydrogenolysis to form TCE (Arnold and Roberts 2000). Alessi and Li (2001) and Loraine (2001) proposed that surfactant modification of ZVI caused a shift in PCE reduction pathways, i.e., a relatively larger proportion of the PCE underwent hydrogenolysis compared to reductive $\beta$-elimination.

\section{Modeling Results}

The average PCE reduction rate constant $\left(\mu_{T}\right)$ values for the surfactant-modified columns were $0.39,0.49$, and $0.65 \mathrm{hr}^{-1}$ at velocities of $0.5,1.0$, and $1.9 \mathrm{~m} \mathrm{~d}^{-1}$, respectively (Table 5).

Table 5. Transport parameter values determined by inverse modeling of the experimental breakthrough data. The number following the \pm sign represents the $95 \%$ confidence limit.

\begin{tabular}{cccccc}
\hline Parameter & $\boldsymbol{v}\left(\mathbf{m ~ d}^{-\mathbf{1}}\right)$ & UM1 & UM2 & SM1 & SM2 \\
\hline \multirow{2}{*}{$\alpha_{L}(\mathrm{~cm})$} & 0.5 & $6.4 \pm 1.7$ & $4.9 \pm 1.2$ & $5.2 \pm 1.3$ & $6.5 \pm 1.7$ \\
& 1.9 & $7.9 \pm 1.3$ & $6.8 \pm 1.0$ & $5.9 \pm 0.9$ & $7.5 \pm 1.2$ \\
\hline \multirow{3}{*}{$\mu_{T}\left(\mathrm{hr}^{-1}\right)$} & 0.5 & $0.107 \pm 0.002$ & $0.120 \pm 0.002$ & $0.42 \pm 0.01$ & $0.36 \pm 0.01$ \\
& 1.0 & $0.152 \pm 0.005$ & $0.165 \pm 0.006$ & $0.51 \pm 0.01$ & $0.47 \pm 0.01$ \\
& 1.9 & $0.190 \pm 0.007$ & $0.192 \pm 0.008$ & $0.68 \pm 0.01$ & $0.62 \pm 0.01$ \\
\hline & 0.5 & 2.0 & 2.2 & 7.8 & 6.7 \\
$\mu_{T, S A}\left(\mathrm{~L} \mathrm{hr}^{-1} \mathrm{~m}^{-2}\right) \times 10^{-4}$ & 1.0 & 2.8 & 3.1 & 9.4 & 8.7 \\
& 1.9 & 3.5 & 3.6 & 12.6 & 11.5 \\
\hline & 0.5 & $0.1 \pm 0.1$ & $0.3 \pm 0.1$ & $2.2 \pm 0.6$ & $1.5 \pm 0.3$ \\
$K_{d}\left(\mathrm{~L} \mathrm{~kg}^{-1}\right)$ & 1.0 & $0.9 \pm 0.2$ & $1.4 \pm 0.4$ & $2.2 \pm 0.4$ & $1.4 \pm 0.4$ \\
& 1.9 & $1.1 \pm 0.1$ & $1.0 \pm 0.1$ & $0.8 \pm 0.2$ & $0.4 \pm 0.2$ \\
\hline
\end{tabular}

These values were roughly three times higher than the $\mu_{T}$ values for the unmodified columns (Table 5). For both surfactant-modified and unmodified columns, the values of $\mu_{T}$ increased linearly (by roughly a factor of 2) as the pore water velocities increased from $0.5 \mathrm{~m} \mathrm{~d}^{-1}$ to $1.9 \mathrm{~m} \mathrm{~d}^{-1}$ (Figure 12). Since the transport experiment with the lowest flow rate was conducted first, the increased $\mu_{T}$ with increasing flow rate indicated that the reactivity of the unmodified and surfactant-modified pellets did not decrease over time. Moreover, the increased $\mu_{T}$ with increasing velocity suggests that the reduction of PCE by the unmodified and surfactantmodified zeolite/ZVI pellets was mass-transfer limited. For mass-transfer-limited surface reactions, increasing the pore water velocity will decrease the thickness of the mass-transfer boundary layer, thereby enhancing the overall reaction rate (Fogler 1999). Others have noted increases in chlorinated hydrocarbon reduction rate constants (in the presence of ZVI) as flow velocities increased in the ranges $0.12-0.61 \mathrm{~m} \mathrm{~d}^{-1}$ (Johnson and Tratnyek 1994), 3.0-12.2 $\mathrm{m} \mathrm{d}^{-1}$ (Mackenzie et al. 1995), and 4.5-17.9 $\mathrm{m} \mathrm{d}^{-1}$ (Casey et al. 2000). Mackenzie et al. (1995) found that the TCE reduction rate constant leveled off at velocities greater than $12.2 \mathrm{~m} \mathrm{~d}^{-1}$, while Gillham and O'Hannesin (1993) found that TCE reduction rate constants were insensitive to velocities in the range $0.6-2.4 \mathrm{~m} \mathrm{~d}^{-1}$. Therefore, reduction rates of halocarbons by ZVI may be controlled by rate of surface reaction and/or rate of diffusive mass transfer, depending upon the characteristics of the ZVI and the conditions of the transport experiments. 


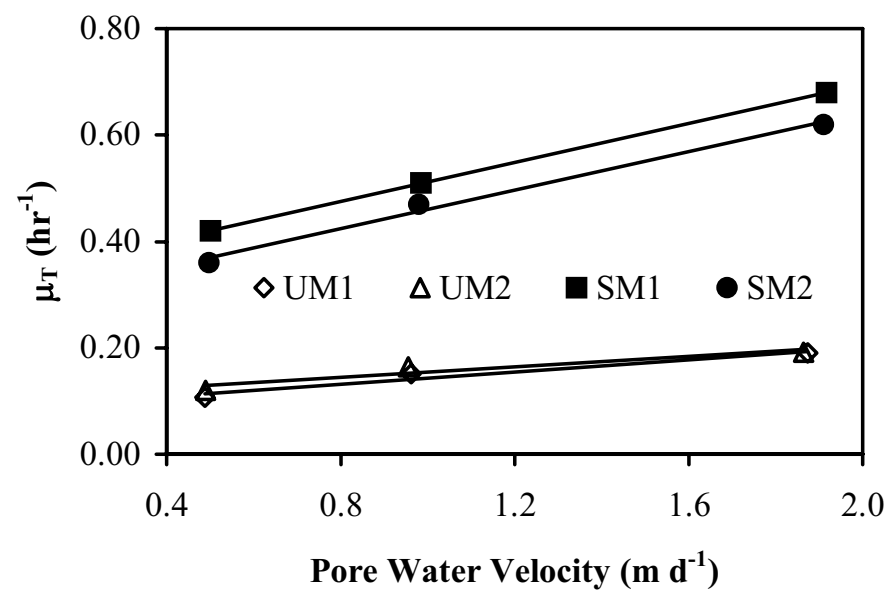

Figure 12. Relationship between PCE reduction rate constant $\mu_{T}$ and pore water velocity. Solid lines represent best linear fits. The $\mathbf{9 5 \%}$ confidence limits for $\mu_{T}$ fall inside the symbols.

PCE reduction rate constants normalized to the surface area concentration of iron $\left(540 \mathrm{~m}^{2} \mathrm{~L}^{-1}\right), \mu_{T, S A}$, ranged from $2.0-12.6 \times 10^{-4} \mathrm{~L} \mathrm{hr}^{-1} \mathrm{~m}^{-2}$ at the three flow rates tested (Table 5). Published values of normalized PCE reduction rate constants range from $10^{-4}-10^{-2} \mathrm{~L} \mathrm{hr}^{-1} \mathrm{~m}^{-2}$ (Johnson et al. 1996). Direct comparison between the normalized rate constant values from this study and the values summarized by Johnson et al. is not straightforward, however, since in Johnson et al. (1996) the rate constants were derived from batch or resident-concentration column experiments that did not account for the dynamics (advection and dispersion) of a flow-through system. Since dispersion affects steady-state breakthrough concentrations during reactive transport (Figure 13), rate constants derived from breakthrough curves are different from those derived from batch or residentconcentration column experiments. Moreover, elevated steady-state breakthrough concentrations with increased dispersion (Figure 13) suggest that extrapolating reduction rate constants from batch or resident-concentration column experiments to flow-through systems may over-predict the performance in the latter. Such may be the case for a pilot-scale ZVI remediation system where the performance did not meet expectations based on the results from resident-concentration experiments (Gillham et al. 1997). 


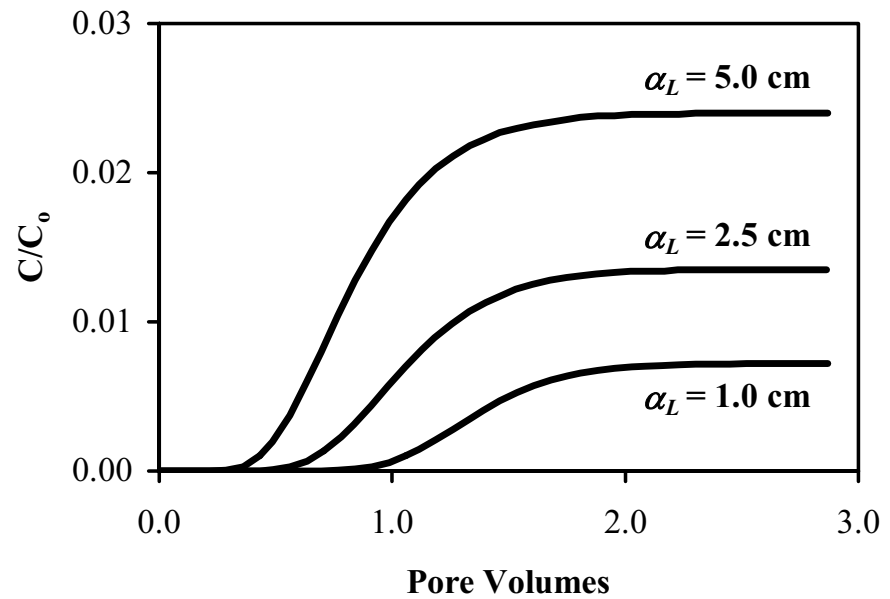

Figure 13. Simulated breakthrough curves for a hypothetical reactive solute using Eq. (3) with different dispersivity $\left(\alpha_{L}\right)$ values. Other transport parameter values $\left(L=0.3 \mathrm{~m}, v=0.5 \mathrm{~m} \mathrm{~d}^{-1}\right.$, $\theta=0.81, \rho_{b}=0.67 \mathrm{~g} \mathrm{~cm}^{-3}, \mu_{T}=0.4 \mathrm{hr}^{-1}$, and $K_{d}=1.0 \mathrm{~L} \mathrm{~kg}^{-1}$ ) were identical. Steady-state breakthrough concentration increases with increasing dispersivity.

The $K_{d}$ values for PCE sorption by the surfactant-modified columns $\left(\sim 2 \mathrm{~L} \mathrm{~kg}^{-1}\right)$ were higher than the $K_{d}$ values for the unmodified columns $\left(\sim 0.2 \mathrm{~L} \mathrm{~kg}^{-1}\right)$ at the lowest flow rate (Table 5). This was expected since the SMZ in the surfactant-modified pellets has a high PCE sorption affinity. For the surfactant-modified columns, the $K_{d}$ values for PCE stayed unchanged as the velocity increased to $1.0 \mathrm{~m} \mathrm{~d}^{-1}$, but decreased as velocity increased to $1.9 \mathrm{~m} \mathrm{~d}^{-1}$ (Table 5). The decreased $K_{d}$ with increasing velocity may be due to the lack of sorption equilibrium. For the unmodified columns, the $K_{d}$ values for PCE increased as velocity increased to $1.0 \mathrm{~m} \mathrm{~d}^{-1}$, then leveled off as the velocity further increased (Table 5). Since PCE sorption sites on the unmodified zeolite/ZVI pellets were limited, it was not clear what caused the $K_{d}$ values to increase with increasing velocity.

Using the PCE $\mu_{T}$ and $K_{d}$ values from Table 5 most relevant to the pilot test $\left(v \approx 0.5 \mathrm{~m} \mathrm{~d}^{-1}\right)$, we simulated the expected concentrations of PCE downgradient from a 1-m-wide SMZ/ZVI barrier. The results are shown in Figure 14. For a $500 \mu \mathrm{g} \mathrm{L}^{-1} \mathrm{PCE}$ plume, the expected steady-state concentration downgradient of the barrier is about $0.025 \mu \mathrm{g} \mathrm{L}^{-1}$, or a more than four order of magnitude reduction, and well below the PCE drinking water standard of $5 \mu \mathrm{g} \mathrm{L}^{-1}$. Thus, we expected the pellets to perform well in the pilot test at OGI. 


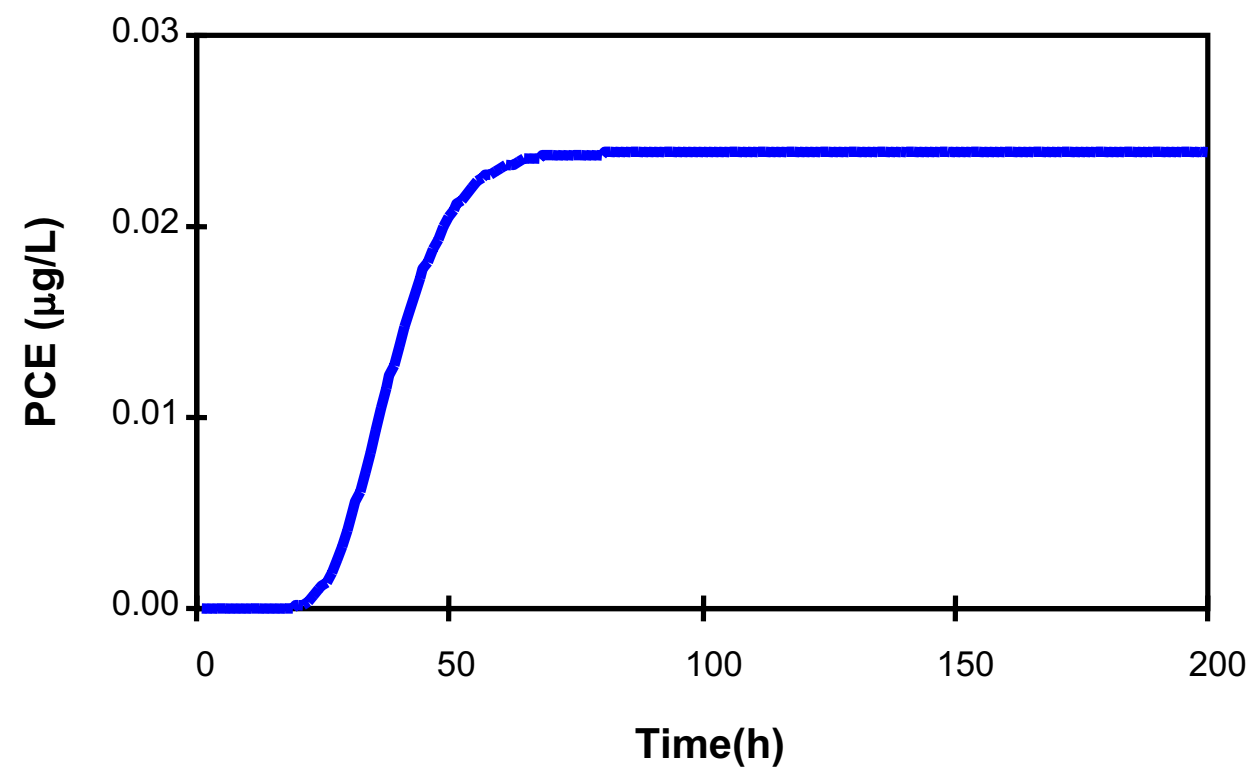

Figure 14. Simulated concentration of PCE downgradient of a 1-m-thick SMZ/ZVI barrier intercepting a $500 \mu \mathrm{g} \mathrm{L}^{-1}$ PCE plume, using Eq. (3). Transport parameters $v=0.5 \mathrm{~m} \mathrm{~d}^{-1}, \theta=0.81, \rho_{b}=0.67 \mathrm{~g} \mathrm{~cm}^{-3}, \mu_{T}=0.4 \mathrm{hr}^{-1}$, and $\left.K_{d}=1.8 \mathrm{~L} \mathrm{~kg}^{-1}\right)$.

\section{Pilot Test of the SMZ/ZVI Permeable Barrier}

Figures 15-19 show chromate and PCE data collected during the pilot test. The data indicate that the SMZ/ZVI cubes were very effective at removing chromate from the groundwater. For samples from within the barrier, chromate was detected only three times and then only at the low level of $0.1 \mathrm{mg} \mathrm{L}^{-1}$, or $1 \%$ of the input concentration. Chromate was fully retained by the barrier, with no detectable concentrations downgradient. No chromate or PCE was detected above background levels underneath the barrier. No measurable concentrations of PCE degradation products (TCE, cis-DCE, trans-DCE, or VC) were observed within or downgradient from the barrier. Sorption/destruction of PCE was not as effective as chromate, however. Figures 18 and 19 indicate that the PCE broke through the barrier within four weeks and that PCE concentrations flowing out of the barrier were, in some cases, greater than $10 \%$ of the influent concentration.

The chromate/PCE contaminant plume was fully captured by the SMZ/ZVI PRB. Although the cross-section views in Figures 16-19 suggest that portions of the chromate and PCE plumes were deflected below the barrier, this apparent plume deflection is an artifact of the plotting of chemical concentration contours. Both chromate and PCE were detected below the 1-m depth upgradient from the barrier. As mentioned above, however, no chromate was detected at any point underneath the barrier or downgradient from it, indicating that the entire plume was focused through the SMZ/ZVI pellets. The PCE detected downgradient of the barrier was due to incomplete reduction by the SMZ/ZVI, not to plume deflection. 
Cr Distribution after 3 days of injection (7/02/01)

PCE Distribution after 6 days of injection (7/02/01)
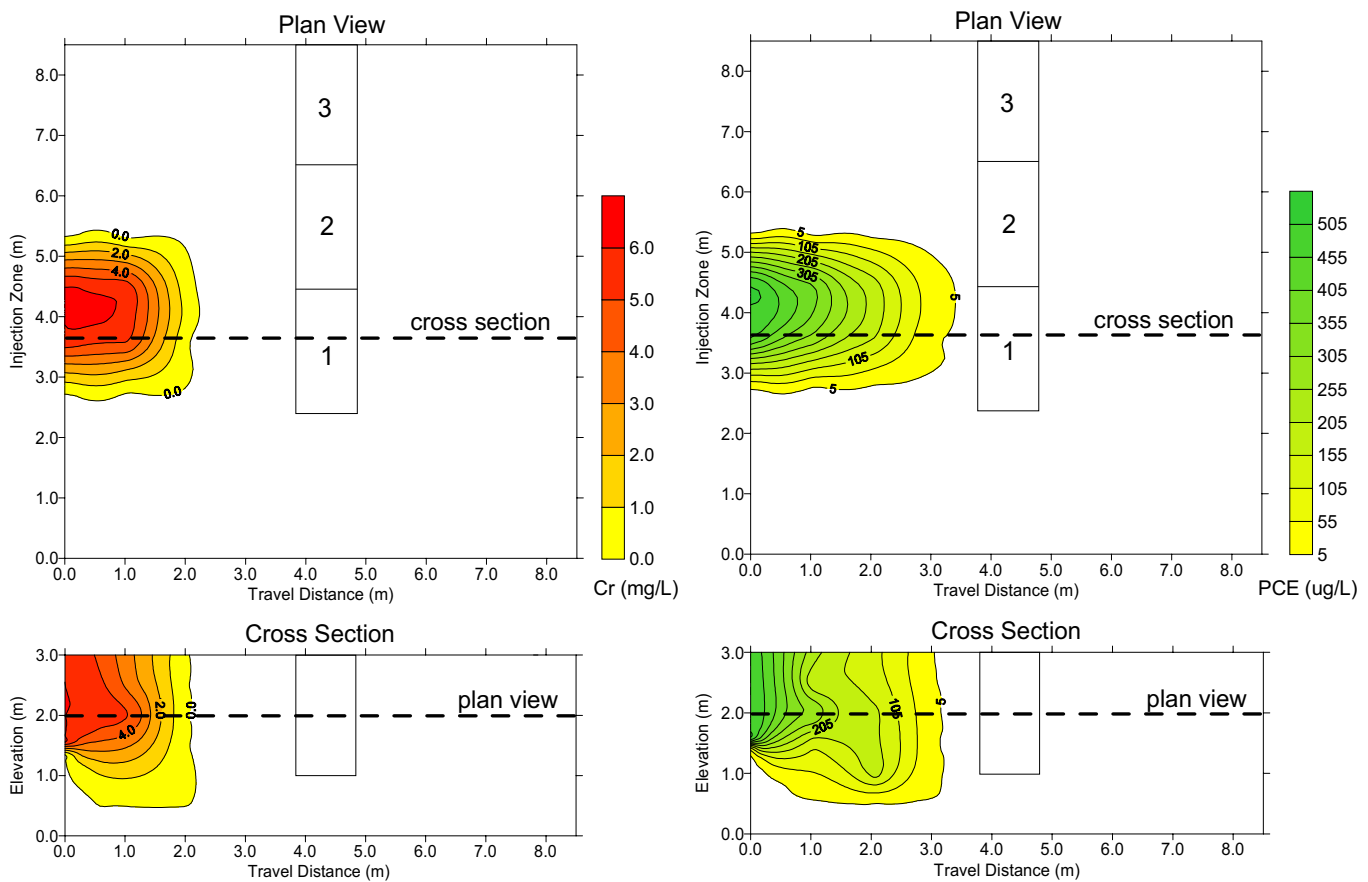

Figure 15. Chromate and PCE distributions following 3-6 days of contaminant injection.

Cr Distribution after 12 days of injection (7/11/01)

PCE Distribution after 15 days of injection (7/11/01)
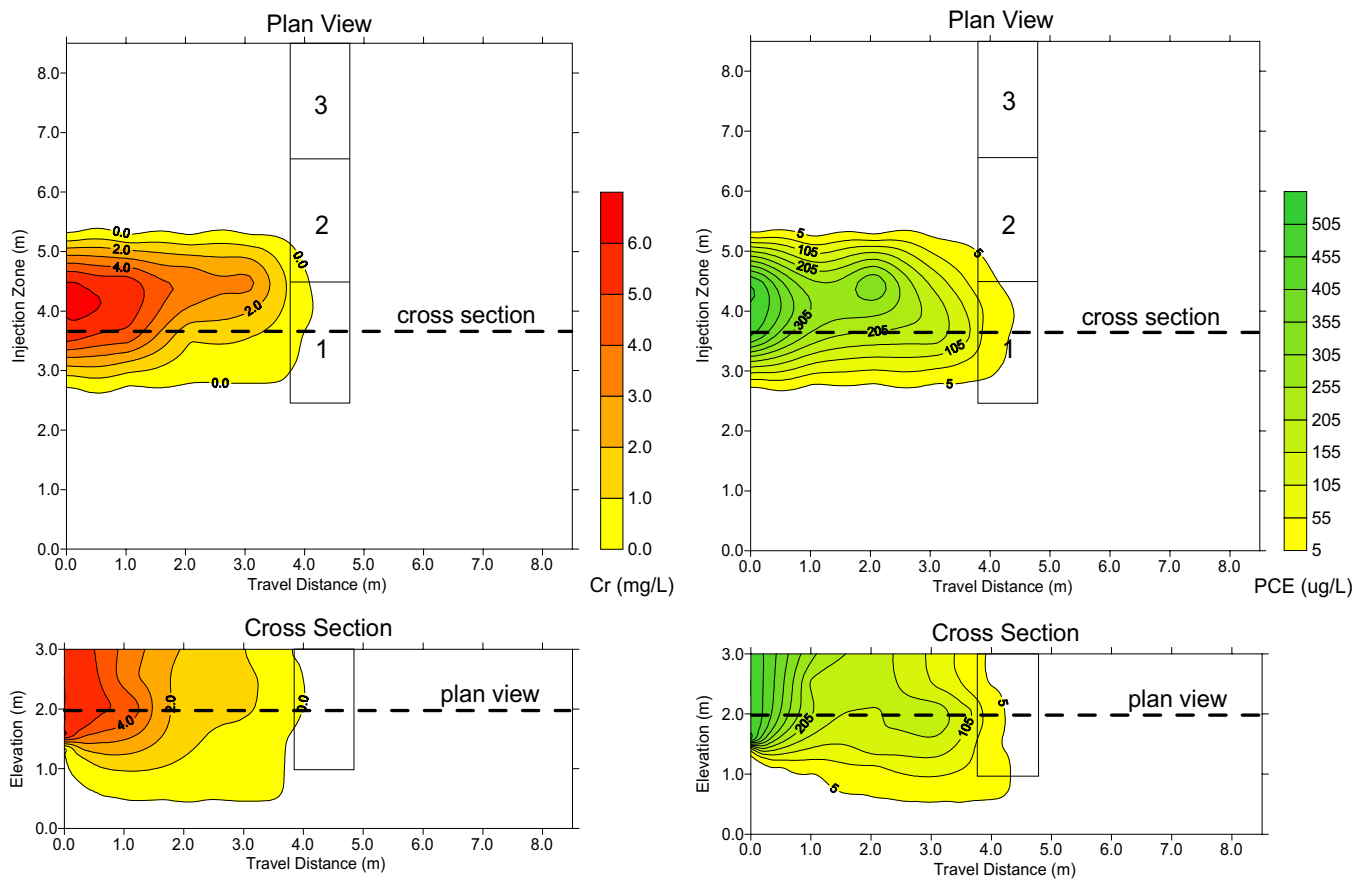

Figure 16. Chromate and PCE distributions following 12-15 days of contaminant injection. 
Cr Distribution after 19 days of injection (7/18/01)

PCE Distribution after 22 days of injection (7/18/01)
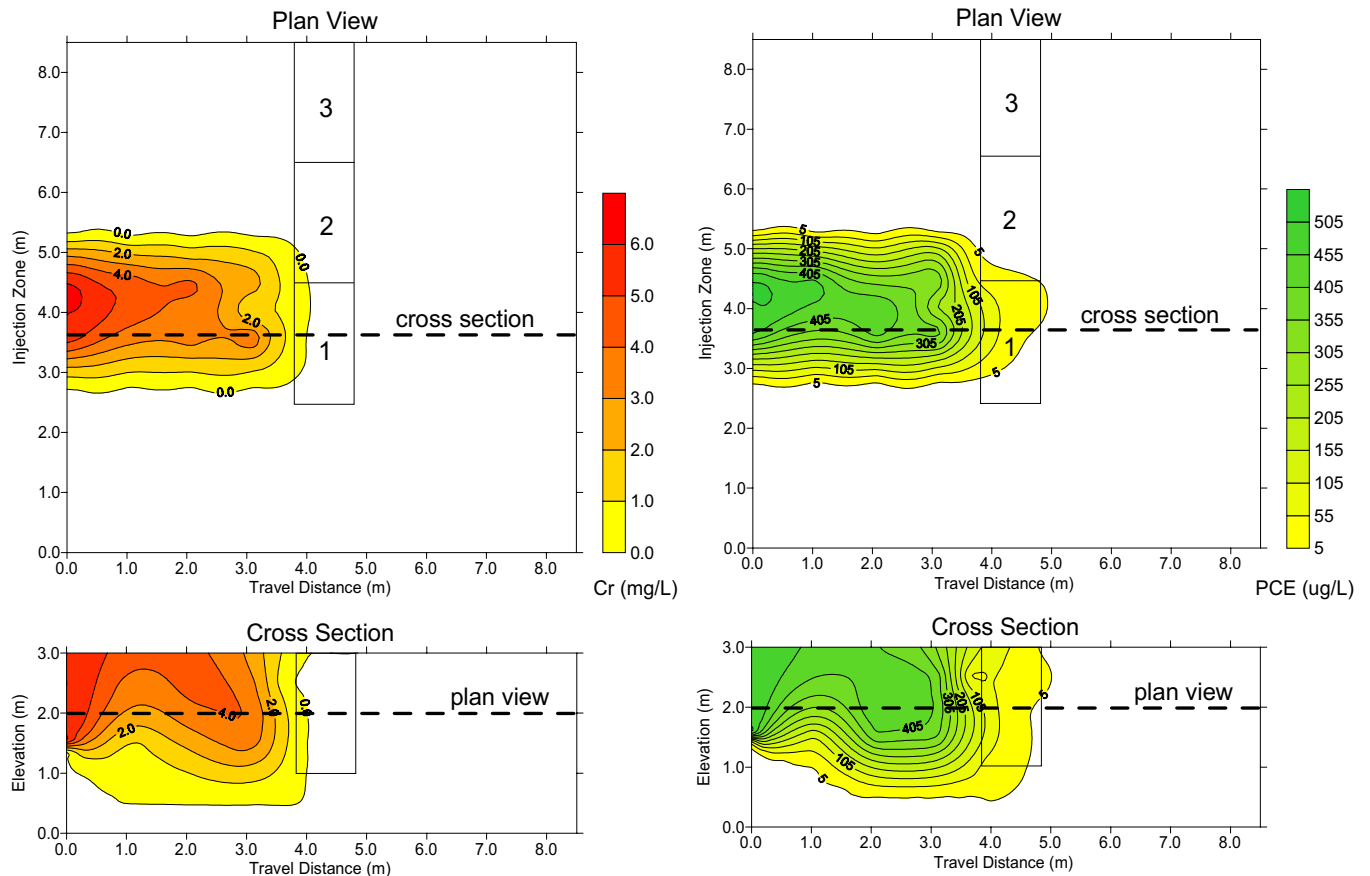

Figure 17. Chromate and PCE distributions following 19-22 days of contaminant injection.

Cr Distribution after 26 days of injection (7/25/01)

PCE Distribution after 29 days of injection (7/25/01)
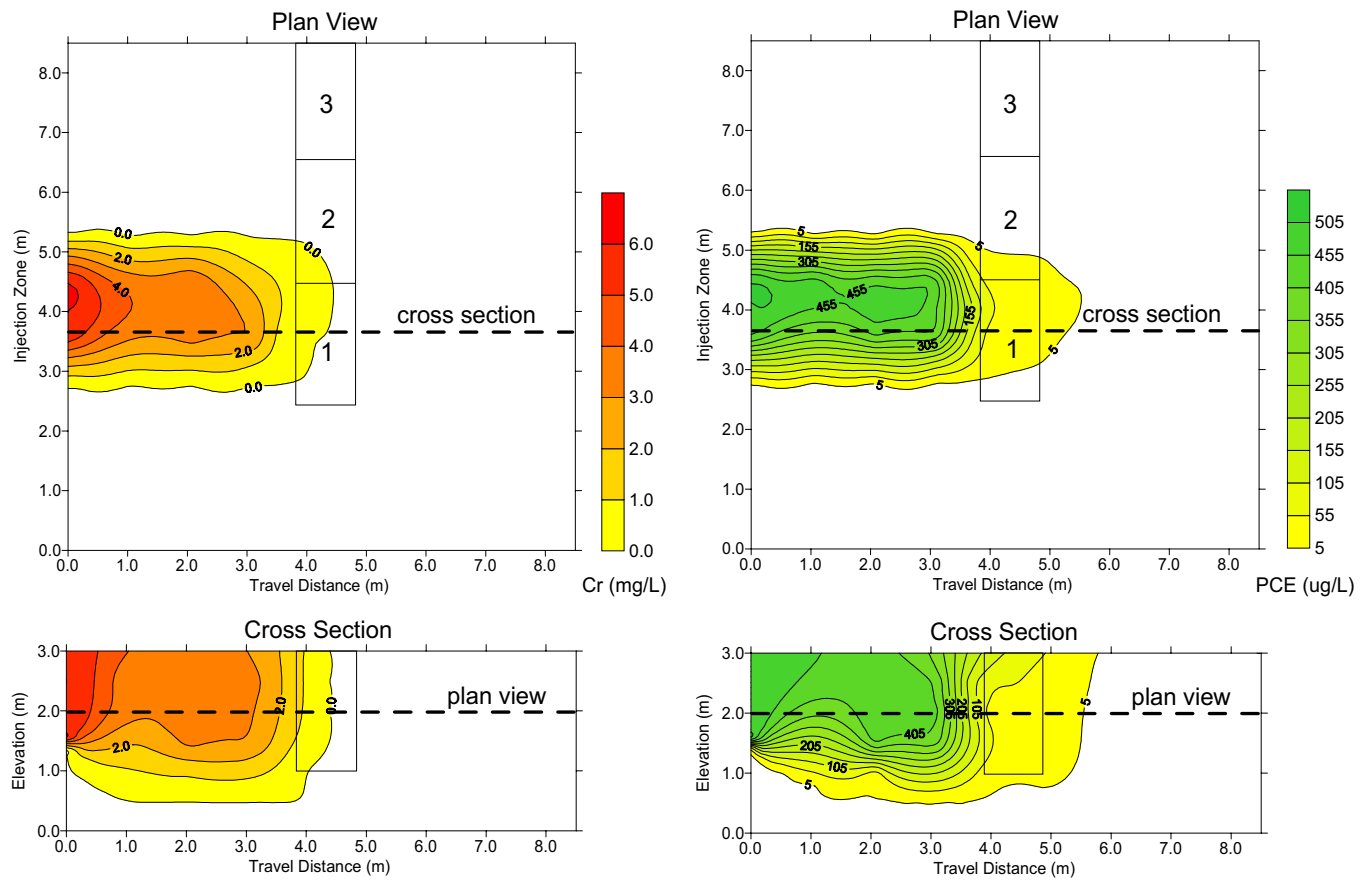

Figure 18. Chromate and PCE distributions following 26-29 days of contaminant injection. 

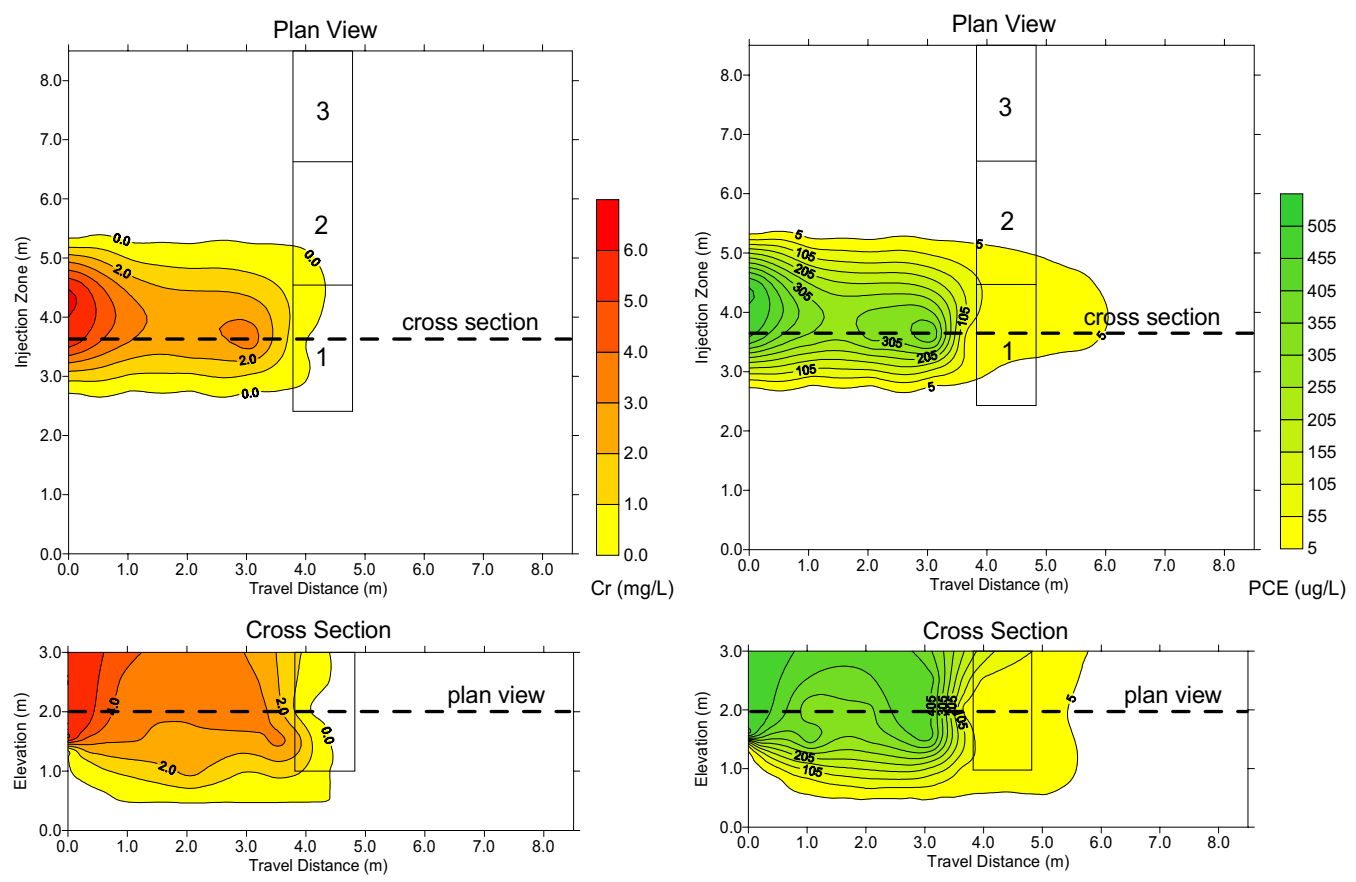

Figure 19. Chromate and PCE distributions following 33-36 days of contaminant injection.

The relatively rapid breakthrough of PCE at significant concentrations was unexpected based on laboratory characterization of the SMZ/ZVI pellets. While the reasons for this early breakthrough have not been fully resolved, three major possibilities stand out. First, due to a miscommunication, the pellets bulk-produced at UDRI contained only about half the optimum surfactant loading determined in preliminary laboratory studies. The PCE reduction rate $\mu_{T}$ is expected to be a strong function of $K_{d}$, and decreases as surfactant loading decreases. The lower $K_{d}$ of the bulk-produced pellets resulted in less efficient reduction of the PCE. Second, the 25-mm SMZ/ZVI cubes used in the pilot test were significantly larger than the pellets used in the laboratory studies. Larger pellets resulted in less efficient mass transfer of intra-pellet and inter-pellet water, effectively limiting PCE's access to the available reactive surface. Third, the $\mathrm{pH}$ of the water within and downgradient from the barrier was well above 9, lowering the PCE dechlorination rate. All three of these factors (reduced SMZ/ZVI reactivity, unfavorable flow geometry, and elevated $\mathrm{pH}$ ) contributed to the differences between laboratory and pilot-test results. 


\section{Conclusions}

\section{Summary of Results}

This project demonstrated that a stable surfactant/zeolite/zero-valent iron (SMZ/ ZVI) pellet could be produced that exhibited superior hydraulic properties and enhanced contaminant reduction compared to SMZ or ZVI alone. Laboratory experiments showed that the presence of surfactant enhanced the reduction of PCE approximately three-fold compared to surfactant-free pellets. Based on these laboratory results, we predicted the concentration of PCE would be lowered by four orders of magnitude upon passing through a 1-m-wide $\mathrm{SMZ/ZVI} \mathrm{barrier.} \mathrm{In} \mathrm{the} \mathrm{pilot-scale} \mathrm{permeable} \mathrm{barrier} \mathrm{test,} \mathrm{although} \mathrm{chromate} \mathrm{was}$ completely removed from the plume, PCE concentrations were reduced only about two orders of magnitude. The contrasts between laboratory and pilot-scale results for PCE are attributed to differences in surfactant loading, flow dynamics, and $\mathrm{pH}$ for the pellets used in the two tests.

While SMZ/ZVI pellets show much promise for permeable barrier applications, more development is required to optimize the pellet formulation and to scale up pellet production. The remainder of this section considers these issues.

\section{Recommendations for Future Work}

\section{Product Adjustments}

The proper amount of surfactant needs to be included in the slurry used to coat the glass foam cubes. Based on laboratory tests of PCE reduction vs. HDTMA loading level, a mass ratio of 1 part HDTMA-Cl (equivalent to 3.44 parts Carsoquat CT-429), 11.5 parts zeolite, and 34.5 parts ZVI is optimal for cube coating.

The pellets should be smaller than the $25-\mathrm{mm}$ cubes used here. Contaminant access to reactive sites in the pellet interiors was likely kinetically limited. Smaller pellets would provide better mass transfer between fluid flowing through the pellet barrier and the reactive sites.

The finished cubes released excess base, resulting in an unacceptably high $\mathrm{pH}$ of water in contact with the cubes. In order to maintain a more neutral $\mathrm{pH}$, some alterations to the pellet formulation are suggested.

Several formulation changes could be made to lessen the alkalinity of the glass foam cubes. First, an increase in the amount of alumina in the final composition of the glass foam could limit the solubility of base-forming sodium silicates, tending to moderate the $\mathrm{pH}$ of water in contact with the pellets. Second, a change in shape of the glass foam material may also be advisable. In a larger-scale production process, the cube shapes could be molded and continuously fired. This would allow for better control and higher firing temperatures, which would result in a more water-resistant end product. Third, a carbon dioxide or other neutralization treatment may be also effective. One possibility would be to place the glass foam pieces in a carbonic acid leaching bath to neutralize residual base. 


\section{Production Enhancements}

The process by which the SMZ/ZVI pellets were produced for this project was highly labor intensive and would not be practical for routine large-scale production. Significant equipment construction and automation would be required in order to produce pellet volumes of hundreds of cubic meters. Ideally, a continuous, automated process would be utilized, beginning with the mixing of slurries to form the glass foam and ending with the packaging of dried pellets. Suggestions for scaling up production and some of the issues involved are discussed below.

Initial molding of the glass foam into the desired final shape could eliminate the breaking step at the end of production. Such molding was attempted during the project using several different types of molds. The molded pieces produced did not always possess the desired porosity or surface area. Some development would be required to optimize the Cercona process to regularly produce a consistent foam cube of the proper dimension.

Upon removal from the mold, the foam cubes could immediately be dried and fired. Experiments conducted by Cercona suggest it may be possible to reduce or eliminate the need to thoroughly dry the ceramic foam prior to firing, particularly for smaller cubes with large open pore structures. A continuous conveyor system is envisioned. The conveyor would move the molded pieces slowly through temperature- and humidity-controlled zones in a drying oven and then through a firing furnace. A number of kilns are commercially available that lend themselves to continuous firing of the ceramic foam. Experimentation would be required to determine an optimal set of drying and firing parameters for the selected pellet shape.

The dried cubes would continue along the conveyor to be sprayed with the surfactant/zeolite/ZVI slurry. After coating, the pellets would undergo a final drying cycle. Sufficient heat is generated by oxidation of the ZVI such that supplementary heat should not be needed for drying, although humidity control and ventilation would be required. After the drying cycle, the pellets would be deposited in the appropriate container.

\section{Production Scale-Up Costs}

The design and construction of a complete processing operation depend upon a number of factors which include but are not limited to the following: production capability in cubic feet per day, availability of used equipment, availability of raw materials, and location of plant where labor and energy costs are favorable. Estimates by Cercona, assuming optimum conditions, suggest that a plant producing 1,000 cubic feet per day, running at 24 hours per day, five days per week could be built for under $\$ 1$ million.

The cost to produce SMZ/ZVI pellets in such a plant is estimated to be roughly $\$ 10$ per cubic foot ( $\$ 350$ per cubic meter). With a bulk density of about $0.67 \mathrm{~g} \mathrm{~cm}^{3}$, the equivalent cost per unit weight would be $\$ 475$ per ton ( $\$ 525$ per metric ton). Such a product could be highly competitive with other existing permeable barrier materials such as ZVI. These cost estimates are, however, highly dependent on the initial plant investment and do not include costs for the studies required for scale-up and production, discussed above. 


\section{References}

Alessi, S. and Z. Li (2001). "Synergistic effect of cationic surfactants on perchloroethylene degradation by zero-valent iron." Environ. Sci. Technol. 35: 3713-3717.

Arnold, W.A. and A.L. Roberts (2000). "Pathways and kinetics of chlorinated ethylene and chlorinated acetylene reaction with $\mathrm{Fe}(0)$ particles.” Environ. Sci. Technol. 34: 17941805 .

Bowman, R.S., G.M. Haggerty, R.G. Huddleston, D. Neel, and M.M. Flynn (1995). Sorption of nonpolar organic compounds, inorganic cations, and inorganic anions by surfactantmodified zeolites. Surfactant-enhanced subsurface remediation. D.A. Sabatini, R.C. Knox, and J.H. Harwell. Washington, DC, American Chemical Society. ACS Symp. Ser. 594: 54-64.

Bowman, R.S., Z. Li, T. Burt, T.L. Johnson, R.L. Johnson, and R. Helferich (1999). Pilot test of an iron/zeolite permeable barrier for destruction of groundwater contaminants. Las Cruces, NM, Waste-management Education and Research Consortium.

Bowman, R.S., Z. Li, S.J. Roy, T. Burt, T.L. Johnson, and R.L. Johnson (1999). Surfacealtered zeolites as permeable barriers for in situ treatment of contaminated groundwater. Pittsburgh, PA, U.S. Dept. of Energy, Federal Energy Technology Center.

Casey, F.S. M., S.K. Ong, and R. Horton (2000). "Degradation and transformation of trichloroethylene in miscible-displacement experiments through zerovalent metals." Environ. Sci. Technol. 34: 5023-5029.

Fogler, H.S. (1999). Elements of Chemical Reaction Engineering. Upper Saddle River, NJ, Prentice Hall.

Gillham, R.W., S.F. O’Hannesin, M.S. Odziemkowski, R.A. Garcia-Delgado, R.M. Focht, W.H. Maulewicz, and J.E. Rhodes (1997). Enhanced degradation of VOCs: laboratory and pilot-scale field demonstration. 2nd International Containment Technology Conference, St. Petersburg, FL, Florida State University.

Gillham, R.W., S.F. O’Hannesin, and J.E. Rhodes (1993). HazMat Central, Chicago, IL.

Helferich, R.L. (1987). Porous ceramic shapes, compositions for the preparation thereof, and method for producing same. USA, The Duriron Company, Inc.: 14.

Johnson, T.L., M.M. Scherer, and P.G. Tratnyek (1996). "Kinetics of halogenated organic compound degradation by iron metal.” Environ. Sci. Technol. 31: 2634-2640.

Johnson, T. L. and P. G. Tratnyek (1994). Proceedings of the 33rd Hanford Symposium on Health \& the Environment - In Situ Remediation: Scientific Basis for Current and Future technologies, Pasco, WA, Battelle Pacific Northwest Laboratories.

Li, Z. (1998). "Degradation of perchloroethylene by zero valent iron modified with cationic surfactant." Adv. Environ. Res. 2: 244-250.

Li, Z. and R. S. Bowman (1997). "Counterion effects on the sorption of cationic surfactant and chromate on natural clinoptilolite.” Environ. Sci. Technol. 31: 2407-2412. 
Li, Z. and R.S. Bowman (1998). "Sorption of perchloroethylene by surfactant-modified zeolite as controlled by surfactant loading." Environ. Sci. Technol. 32: 2278-2282.

Li, Z., H.K. Jones, R.S. Bowman, and R. Helferich (1999). "Enhanced degradation of chromate and PCE by pelletized surfactant-modified zeolite/zerovalent iron." Environ. Sci. Technol. 33: 4326-4330.

Loraine, G.A. (2001). "Effects of alcohols, anionic and nonionic surfactants on the reduction of PCE and TCE by zero-valent iron.” Water Res. 35: 1453-1460.

Mackenzie, P.D., S.S. Baghel, G.R. Eykholt, D.P. Horney, J.J. Salvo, and T.M. Sivavec (1995). American Chemical Society Natl. Mtg., American Chemical Society. 35:796-799.

Naftz, D.L., S.J. Morrison, E.M. Feltcorn, G.W. Freethey, C.C. Fuller, M.J. Piana, R.G. Wilhelm, R.C. Rowland, J.A. Davis, and J.E. Blue (2000). EPA 402-C-00-001. U.S. Environmental Protection Agency.

O'Hannesin, S.F. and R.W. Gillham (1998). "Long-term performance of an in situ 'iron wall' for remediation of VOCs.” Ground Water. 36: 164-170.

Puls, R.W., C.J. Paul, and R.M. Powell (1999). "The application of in situ permeable reactive (zero-valent iron) barrier technology for the remediation of chromate-contaminated groundwater: a field test." Applied Geochem. 14: 989-1000.

Šimunek, J., K. Huang, M. Šejna, and M.Th. van Genuchten (1998). The HYDRUS-1D software package for simulating the one-dimensional movement of water, heat, and multiple solutes in variably-saturated media. Riverside, CA, U.S. Salinity Laboratory, USDA-ARS.

Sullivan, E. J., D.B. Hunter, and R.S. Bowman (1997). "Topological and thermal properties of surfactant-modified clinoptilolite studied by tapping-mode atomic force microscopy and high-resolution thermogravimetric analysis." Clays Clay Miner. 45(1): 42-53.

Weber, E.J. (1996). "Iron-mediated reductive transformations: Investigation of reaction mechanism.” Environ. Sci. Technol. 30: 716-719. 


\section{Acronyms and Abbreviations}

$\begin{array}{ll}C & \text { solute concentration in aqueous phase } \\ D & \text { hydrodynamic dispersion coefficient } \\ \text { DCE } & \text { dichloroethylene } \\ \text { DDTMA } & \text { dodecyltrimethylammonium } \\ \text { FID } & \text { flame ionization detector } \\ \text { HDTMA } & \text { hexadecyltrimethylammonium } \\ K_{d} & \text { distribution coefficient } \\ \text { NMT } & \text { New Mexico Institute of Mining and Technology } \\ \text { OGI } & \text { Oregon Graduate Institute } \\ \text { OTMA } & \text { octyltrimethylammonium } \\ \text { PCE } & \text { perchloroethylene } \\ \text { PRB } & \text { permeable reactive barrier } \\ \text { PV } & \text { pore volume } \\ S & \text { solute concentration in solid phase } \\ \text { SM } & \text { surfactant-modified pellets } \\ \text { SMZ } & \text { surfactant-modified zeolite } \\ t & \text { time } \\ \text { TCE } & \text { trichloroethylene } \\ \text { UDRI } & \text { University of Dayton Research Institute } \\ \text { UM } & \text { unmodified pellets } \\ v & \text { velocity } \\ \text { VC } & \text { vinyl chloride } \\ x & \text { distance } \\ \text { ZVI } & \text { zero-valent iron } \\ \alpha_{L} & \text { longitudinal dispersivity } \\ \theta & \text { porosity } \\ \mu_{L} & \text { aqueous phase first order decay constant } \\ \mu_{S} & \text { solid phase first order decay constant } \\ \mu_{T} & \text { overall first order reaction rate constant } \\ \rho_{b} & \text { sediment bulk density } \\ & \end{array}$

